\title{
Improved nonclinical pharmacokinetics and biodistribution of a new PPAR pan-agonist and COX inhibitor in nanocapsule formulation
}

\author{
Giani Martins Garcia a,b, Líliam Teixeira Oliveira ${ }^{\mathrm{a}, \mathrm{b}}$, Ivan da Rocha Pitta ${ }^{\mathrm{c}}$, Maria do Carmo Alves de Lima ${ }^{\mathrm{c}}$, \\ José Mário Carneiro Vilela ${ }^{\mathrm{d}}$, Margareth Spangler Andrade ${ }^{\mathrm{d}}$, \\ Dulcinéia Saes Parra Abdalla ${ }^{e}$, Vanessa Carla Furtado Mosqueira ${ }^{\mathrm{a}, \mathrm{b}, *}$

\footnotetext{
a Núcleo de Pesquisa em Ciências Biológicas, Programa de Pós-Graduação em Ciências Biológicas, Universidade Federal de Ouro Preto, Minas Gerais, Brazil

b Laboratório de Desenvolvimento Galênico e Nanotecnologia-CiPharma, Escola de Farmácia, Universidade Federal de Ouro Preto, Minas Gerais, Brazil

c Laboratório de Planejamento e Síntese de Fármacos, Universidade Federal de Pernambuco, Brazil

e Departamento de Análises Clínicas, Faculdade de Ciências Farmacêuticas, Universidade de São Paulo, Brazil
} \\ d Centro Tecnológico CETEC SENAI-Departamento Regional de Minas Gerais, Belo Horizonte, Minas Gerais, Brazil
}

\section{A R T I C L E I N F O}

Article history:

Received 17 October 2014

Received in revised form 16 April 2015

Accepted 25 April 2015

Available online 27 April 2015

Chemical compounds studied in this article: Poly(D,L-lactide) (PubChem CID: 24877805) Poloxamer 188 or Polyoxyethylene-

polyoxypropylene Block Copolymer (PubChem

CID: 10129990)

LYSO-7 or [(5Z)-5-[5-bromo-1H-indol-3-

yl)methylene]-3-(4-chlorobenzyl)-

thiazolidine-2,4-dione] (CAS Registry Number 1505484-42-3)

Keywords:

Thiazolidinedione

Nanocapsules

Peroxisome proliferator-activated receptor- $\gamma$

agonist

Bioanalytical method

Pharmacokinetics

Biodistribution

\begin{abstract}
A B S T R A C T
We report the in vitro release profile and comparative pharmacokinetics and biodistribution of a new peroxisome proliferator-activated receptor- $\gamma$ agonist and cyclooxygenase inhibitor (Lyso-7) free or associated to poly (D,Llactic acid) nanocapsules (NC) after intravenous administration in mice. Lyso-7 pertains to the class of insulinsensitizing agents that shows potential beneficial effects in diabetes therapy. Monodispersed Lyso-7 NC with a mean diameter of $273 \mathrm{~nm}$ with high encapsulation efficiency (83\%) were obtained. Lyso-7 dissolution rate was reduced (2.6-fold) upon loading in NC. The pharmacokinetic parameters were determined using a noncompartmental approach. In comparison with Lyso-7 in solution, the plasma-AUC increased 14-fold, the mean residence time 2.6-fold and the mean half-life $\left(t_{1 / 2}\right) 1.5$-fold for Lyso-7-NC; the Lyso-7 plasma clearance, distribution volume and elimination rate were reduced 13,10 and 1.4 fold, respectively, which indicates higher retention of encapsulated Lyso-7 in the blood compartment. Upon association with NC, organ exposure to Lyso-7 was higher in the heart (3.6-fold), lung (2.8-fold), spleen (2.3-fold), kidney (2-fold) and liver (1.8-fold) compared to Lyso-7 in solution. The analysis of whole data clearly indicates that body exposure to Lyso-7 was enhanced and the general toxicity reduced upon nanoencapsulation, allowing further evaluation of Lyso-7 in nonclinical and clinical studies
\end{abstract}

(c) 2015 Elsevier B.V. All rights reserved.

\section{Introduction}

Thiazolidinediones (TZD) are drugs used in diabetes treatment as insulin-sensitizing agents $[1,2]$. They are peroxisome proliferatoractivated receptor- $\gamma$ (PPAR- $\gamma$ ) synthetic ligands. The PPAR- $\gamma$ participates in adipose and vascular cell differentiation [1-3]. Examples of marketed TZDs are pioglitazone, rosiglitazone and troglitazone, but the latter two have been withdrawn from the market [4,5]. Despite

\footnotetext{
* Corresponding author at: Laboratory of Pharmaceutics and Nanobiotechnology, Escola de Farmácia/UFOP, Campus Universitário Morro do Cruzeiro, Ouro Preto, CEP 35400-000 Minas Gerais, Brazil.

E-mail addresses: mosqueira@ef.ufop.br, vamosqueira@gmail.com (V.C.F. Mosqueira).
}

beneficial impact on therapy management of diabetes and metabolic syndrome, serious side effects are reported for the most common TZDs, such as hepatic and hematologic toxicity and body weight gain [4]. In this sense, the search for new, less toxic, TZD analogs is an important task to be undertaken.

New chemical entities pertaining to this class of compounds have recently been investigated, particularly due to in vitro and in vivo antiinflammatory properties associated with cyclooxygenase (COX) inhibition [6-10]. A 5-indol substitution on the central thiazolidinic ring and the absence of a sulfonyl moiety are two structural features of a chemical series obtained, which are chemically related to indomethacin (anti-inflammatory) and roziglitazone (used in type-2 diabetes mellitus treatment) $[9,10]$. One of the compounds of this series is Lyso-7 (1), 
<smiles>O=C1S/C(=C\c2c[nH]c3ccc(Br)cc23)C(=O)N1Cc1ccc(Cl)cc1</smiles><smiles>O=C(Cn1ccnc1[N+](=O)[O-])NCc1ccccc1</smiles>

Fig. 1. Chemical structures of Lyso-7 (1) and benznidazole (2).

the (5Z)-5-[(5-bromo-1H-indol-3-yl)methylene]-3-(4-chlorobenzyl)thiazolidine-2,4-dione) (Fig. 1) [10,11]. Lyso-7 down-regulates the production of several inflammatory cytokines, such as IL-1 $\beta$ and NO by mice neutrophils, confirming its effects on the inflammatory response [10]. Santin et al. recently showed that Lyso-7 reduced the neutrophil recruitment to inflammation sites at lower doses $(3 \mathrm{mg} / \mathrm{kg}$ ) than those required by indomethacin $(10 \mathrm{mg} / \mathrm{kg})$, celecoxib $(10 \mathrm{mg} / \mathrm{kg})$ or pioglitazone $(50 \mathrm{mg} / \mathrm{kg}$ ) after oral administration to mice [10]. Lyso-7 higher efficacy in the above-mentioned study reflects two combined actions: the activation of PPAR- $\gamma$ that influences the complex process of cellular migration to the inflammation sites, and the inhibition of COX enzymes [10]. The authors also demonstrated that oral administration of $25 \mathrm{mg} / \mathrm{kg}$ of Lyso-7 protects $\mathrm{Et} / \mathrm{HCl}$-induced gastric tissue damage through the inhibition of neutrophil migration and the change in the eNOS/iNOS balance in mice [11]. Thus, Lyso-7 is a promising compound that may be applied in the treatment of inflammatory diseases. Furthermore, Lyso-7 has partial action as an agonist of PPAR- $\alpha$ and $\beta / \delta$, which supports its function as PPAR pan-agonist $[10,11]$. It was suggested that PPAR pan-agonists have beneficial effects in the therapy of patients with metabolic syndrome [4,5].

Low water solubility of Lyso-7 leads to insufficient oral bioavailability in agreement with Lipinski's rules (estimated $\log p=5.64(\mathrm{ACD} /$ $\left.\mathrm{Lab}^{\odot}\right)$ ). Its limited solubility requires pre-formulation strategies even in the initial steps of pre-clinical evaluation and it is of critical importance in commercial drug product development [12]. Thus, Lyso-7 in nanodispersed dosage form, which could be suitable for oral or intravenous administration, is proposed herein to overcome this issue. Nanometric drug delivery systems improve hydrophobic drug dispersion in water, allow controlled release profiles and frequently alter the pharmacokinetics and biodistribution of the associated drug [13]. Polymeric delivery nanocarriers, such as nanocapsules (NC), possess high capacity of encapsulation of poorly water soluble substances and represent an alternative system to deliver lipophilic drugs [13]. Furthermore, it was recently reported that encapsulation of the TZD, pioglitazone, into polymeric nanoparticles increased the efficacy of neovascularization in hindlimb ischemia model improving drug therapeutic effect in mice [14].

Lyso-7 is an original substance and the development of analytical and bioanalytical methods for its assay is essential in order to carry out preclinical studies. In this context, we developed Lyso-7 nanocapsules and determined the Lyso-7 dissolution/release profile in vitro, major pharmacokinetics parameters and the biodistribution profiles of Lyso-7 in its free form and in polymeric NC dosage form. To attain this goal we developed and validated accurate, specific, rapid and sensitive high performance liquid chromatography with ultraviolet detection (HPLC-UV) methods to quantify Lyso-7 in the NC dosage forms and in biological matrices, such as the plasma, spleen, liver, heart, lung and kidney of mice. Furthermore, we estimated Lyso-7 red blood cell toxicity considering that it is the first reported intravenous dosage form and as such blood biocompatibility studies were required.

\section{Materials and methods}

\subsection{Chemicals and reagents}

Lyso-7, [(5Z)-5-[5-bromo-1H-indol-3-yl)methylene]-3-(4-chlorobenzyl)-thiazolidine-2,4-dione] (CAS Registry Number 1505484-42-3) (1), Mw $447.73 \mathrm{~g} / \mathrm{mol}, \log p=5.642$ (calculated by ACD/Lab software V11.02@) was synthesized, purified and provided by Prof. Ivan da Rocha Pitta (UFPE), as recently reported [10,11]. Benznidazole (BZ) (N-benzyl-(2-nitro-1H-imidazol-1-yl), Mw $260.25 \mathrm{~g} / \mathrm{mol}$, purity $99.85 \%$ (2) (Fig. 1), Poloxamer ${ }^{\circledR} 188$ and polymer poly-rac-lactide (PLA), Mn 75,000-120,000 g/mol, Tween ${ }^{\circledR} 80$, Polyethylene glycol 300 and methanol (HPLC grade) were purchased from Sigma-Aldrich (Brazil). Symplicity ${ }^{\circledR}$ System (Millipore, Bedford, USA) was used to produce Milli-Q water, which was used to prepare all solutions throughout the experiments. Soy lecithin (Epikuron ${ }^{\circledR} 170$ ) was provided by Lucas Meyer (France) as a kind gift. Mygliol $810 \mathrm{~N}$ was provided by Hulls (Germany). Ethyl acetate, $\mathrm{N}, \mathrm{N}$-dimethylacetamide (DMA) and dimethylsulfoxide (DMSO) (analytical grade) were provided by Tedia (Rio de Janeiro, Brazil).

\subsection{Nanocapsule preparation and characterization}

Biodegradable Lyso-7 nanocapsules (Lyso-7 NC) were prepared with poly-rac-lactide (PLA) using a similar methodology and formulation as previously reported by Mosqueira et al. $[13,15]$ and first described by Fessi et al. [16] for a final concentration of $0.5-1.0 \mathrm{mg} / \mathrm{ml}$ of Lyso-7 in the NC formulation. Briefly, Lyso-7-loaded PLA NC were prepared as follows: $0.6 \% \mathrm{wt} / \mathrm{v}$ of PLA, $0.75 \% \mathrm{v} / \mathrm{v}$ of oil, and $0.75 \% \mathrm{wt} / \mathrm{v}$ of soy lecithin were dissolved in $10 \mathrm{ml}$ of acetone. This clean organic solution was injected at a constant flow rate with a syringe into the aqueous solution containing $0.75 \% \mathrm{wt} / \mathrm{v}$ of Poloxamer ${ }^{\circledR} 188(20 \mathrm{ml})$, and the final mixture was maintained under magnetic stirring for $10 \mathrm{~min}$. Then, all organic solvents and part of the water were evaporated under reduced pressure (Heidolph Rotary Evaporator, Germany) to render $5 \mathrm{ml}$ of aqueous suspension of NC.

Quasi-elastic light scattering (QELS) (Nanosizer N5 Plus, BeckmannCounter, USA) analysis of NC samples was performed at $90^{\circ}$ to determine the mean hydrodynamic diameter and polydispersion of the particle population in three different NC batches. The zeta potential $(\zeta)$ measurements were made using Laser Doppler Anemometry (LDA) (Zetasizer 3000 HS, Malvern Instruments, UK) after diluting the NC in $1 \mathrm{mM} \mathrm{NaCl}$ (250-fold), with total conductivity of the colloidal suspensions maintained as constant as possible $(110 \pm 5 \mu \mathrm{S} / \mathrm{cm})$.

\subsection{Drug encapsulation efficiency and drug payload in nanocapsules}

The efficiency of the process of Lyso-7 encapsulation in the NC was calculated following Eq. (1), as previously reported elsewhere [17]. Lyso-7 encapsulation efficiency \% (EE) represents the weight percentage of feed lyso-7 that was encapsulated in the preparation process, considering that the fraction that was not encapsulated was present in the ultrafiltrate. The payload \%, representative of the drug/polymer mass ratio in the final formulation, is defined herein as the percentage mass of Lyso-7 associated to NC per mass of polymer in the NC final product (Eq. (2)). The payload \% gives an insight into the capacity of 
the nanocapsules to transport the drug.

Lyso -7 encapsulation efficiency $\%=\frac{C^{\text {final product }}-C^{\text {ultrafiltrate of the final product }}}{C^{\text {drug feeding }}} \times 100$

Payload $\%=\frac{\text { mass of drug encapsulated in the NCfinal formulation }(\mathrm{mg} / \mathrm{ml})}{\text { mass of polymer in the formulation }(\mathrm{mg} / \mathrm{ml})} \times 100$

The amount of Lyso-7 not encapsulated and dissolved in the external phase was found in the ultrafiltrate after centrifuging the samples in AMICON device (Microcon, $50 \mathrm{kDa}$ MWCO, Millipore ${ }^{\circledR}$ ) at $500 \times \mathrm{g}$ for 40 min under tangential flow. The ultrafiltrate $(50 \mu \mathrm{l})$ was mixed with acetonitrile $(200 \mu \mathrm{l})$, centrifuged and the supernatant assayed in HPLC. The Lyso-7 encapsulated in NC was retained in the upper part of the ultrafilter. The total amount of Lyso-7 in the NC suspension was assessed by dissolving $80 \mu \mathrm{l}$ of the NC suspension in $920 \mu \mathrm{l}$ of methanol, mixing on a vortex for 5 min (Vortex Instruments, IKA, Germany). Then, the solution was centrifuged and the drug in the supernatant $(50 \mu \mathrm{l})$ was quantified using the analytical method. The samples were filtered ( $0.45 \mu \mathrm{m}, 4 \mathrm{~mm}$ filters) before HPLC injection and the analyses were performed in triplicate.

\subsection{Nanocapsule surface morphology}

Morphological evaluation and additional size analysis of the NC were performed using Atomic Force Microscopy (AFM). On a freshly cleaved mica support, $5 \mu$ of sample was deposited, spread on and dried with a stream of argon. AFM analyses were performed at room temperature, on Dimension 3000 equipment monitored by a Nanoscope IIla controller (Digital Instruments, Santa Barbara/USA). The images were obtained in tapping mode, using commercial Si probes (Nanosensors) with cantilevers having a length of $228 \mu \mathrm{m}$, resonance frequencies of $75-98 \mathrm{kHz}$, spring constants of 3.0-7.1 N/m, a nominal tip curvature radius range from 5 to $10 \mathrm{~nm}$ and scan rate of $1 \mathrm{~Hz}$. Data treatment and dimensional analysis were carried out using the software provided with the equipment (Section of Analyses).

Scanning electron microscopy (SEM) analyses were performed on Lyso 7 PLA NC in order to observe morphology, size dispersion and surface characteristics. NC samples were deposited on a glass slide, allowed to dry at room temperature under vacuum and coated with gold (Q150R ES, Quorum/UK). The samples were examined by SEM using a MIRA-3 field emission gain equipment (Tescan, USA) applying a potential of $20 \mathrm{kV}$. SEM images of NC were recorded at different magnifications.

\subsection{Hemolytic toxicity}

The hemolysis was assayed by colorimetric measurement of the hemoglobin release after incubation with samples. Blood was collected from healthy female mice $(n=3)$ with heparin, centrifuged and the plasma was discarded. The red blood cells (RBC) were diluted in PBS ( $157 \mathrm{mM}$ ) in order to reach an absorbance of 0.4 at $540 \mathrm{~nm}$ wavelength. The hemolysis experiments were performed in accordance with Dobrosvolskaia et al., with some modifications [18]. Three controls were used: $T_{0}$ cells incubated with PBS (no hemolysis or negative control), $\mathrm{T}_{100}$ cells incubated with Triton $2 \%$ in water (total hemolysis or positive control), and $\mathrm{T}_{\mathrm{i}}$ control sample without blood incubated with blank-NC (reference of NC turbidity). The absorbance of the hemolysis assay was subtracted to the absorbance of the $T_{i}$ at each concentration tested. Free Lyso-7 and Lyso-7 loaded in PLA NC were added $(100 \mu \mathrm{l})$ to $900 \mu \mathrm{l}$ of the RBC solution. The concentrations tested were $25,50,75$ and $100 \mu \mathrm{g} / \mathrm{ml}$ of free Lyso-7 in solution and in NC. All the samples were incubated for $3 \mathrm{~h}$ at $37^{\circ} \mathrm{C}$, hemolysis was stopped in an ice-bath and the not lysed cells were removed by centrifugation $\left(5 \mathrm{~min}\right.$ at $500 \times \mathrm{g}$ at $4{ }^{\circ} \mathrm{C}$ ). The supernatant was collected and analyzed by UV-vis spectroscopy at $540 \mathrm{~nm}$ using the Helios- $\alpha$ spectrophotometer (Thermo Electron Corporation, USA). The results were expressed as percentage of hemolysis by the following equation, where $\mathrm{T}$ is the absorbance of the supernatant sample: \% hemolysis = $\left.\left[\left(\mathrm{T}-\mathrm{T}_{\mathrm{i}}\right)-\mathrm{T}_{0}\right)\right] \times 100 / \mathrm{T}_{100}$.

\subsection{Instrumentation and chromatographic conditions}

To quantify Lyso-7 high performance liquid chromatographic (HPLC) system (Waters Alliance 2695) was used that includes a separation module with autosampler, pump column oven $\left(35^{\circ} \mathrm{C}\right)$ and UV detector (Waters 2489) set at $385 \mathrm{~nm}$ wavelength. C18-RP Phenomenex column $(150 \mathrm{~mm} \times 4.6 \mathrm{~mm}, 4 \mu \mathrm{m})$ was protected by security guard column (Phenomenex C18-RP, $2 \mathrm{~mm} \times 4.6 \mathrm{~mm}, 3 \mu \mathrm{m}$ ). The methanol/water $(90: 10 \mathrm{v} / \mathrm{v})$ was the isocratic mobile phase, pumped at $1 \mathrm{ml} / \mathrm{min}$. The injection volumes were $50 \mu \mathrm{l}$ and $25 \mu \mathrm{l}$, in analytical and bioanalytical methods, respectively. Each sample was analyzed in triplicate in HPLC.

The analytical method to quantify Lyso-7 in the NC formulation was developed according to the guidelines of the International Conference on Harmonization (ICH) [19]. The selectivity of the method in the presence of potential interfering substances, such as polymers, oil and other excipients used in the NC formulations was analyzed by injecting defined concentration of drug-free PLA NC and Lyso-7 PLA NC. Linear regression analysis of the calibration curve (Lyso-7 peak area versus concentration) was performed to determine linearity. The equations $\mathrm{LOD}=3.3 \mathrm{\sigma} / \mathrm{S}$ and $\mathrm{LOQ}=10 \mathrm{\sigma} / \mathrm{S}$ were used to calculate the limits of detection (LOD) and of quantification (LOQ), respectively, where $S$ is the slope of the calibration curve and $\sigma$ represents the standard deviation of y-intercepts in the regression curves. In order to determine the precision and accuracy, quality-control samples of Lyso-7 were prepared at concentrations of 1,10 and $75 \mu \mathrm{g} / \mathrm{ml}(n=5)$ on three different validation days.

\subsection{Lyso-7 dissolution/release profile in vitro}

Firstly, Lyso-7 equilibrium solubility was determined in the release medium, i.e. phosphate buffered saline (PBS), at pH 7.4. Lyso-7 (2 mg) was maintained under stirring with $2 \mathrm{ml}$ of PBS during $24 \mathrm{~h}$ at $37^{\circ} \mathrm{C}$. At the end of this period, the solution was centrifuged at $1000 \times g$ and a sample of the supernatant was withdrawn and diluted in methanol to be quantified by HPLC using the analytical method described herein. The in vitro Lyso-7 dissolution/release studies were performed using the reverse dialysis technique [20]. Dialysis bags (12-14 kDa MWCO) containing $1 \mathrm{ml}$ of PBS were immersed in $500 \mathrm{ml}$ of PBS. Lyso-7 PLA NC ( $4 \mu \mathrm{g} / \mathrm{ml}$ ) was added to the medium outside of the dialysis bags, respecting sink conditions (20\% of saturation solubility). At predetermined time-intervals (15, 30, 60, 180, 360, 720 and $1440 \mathrm{~min})$, a dialysis bag was removed from the medium, $500 \mu \mathrm{l}$ was collected, diluted in $500 \mu \mathrm{l}$ of methanol and quantified by HPLC-UV. Mathematical models (Higuchi, zero-order, first-order and Korsmeyer-Peppas) were used to analyze the Lyso-7 dissolution and release data.

\subsection{Development and validation of bioanalytical method}

\subsubsection{Animals}

Healthy female Swiss mice weighing 29-31 g were provided by UFOP animal facility (CCA) and maintained according to the guidelines established by the Brazilian College of Animal Experimentation (COBEA). The experiments were submitted and approved by the Ethical Committee on Animal Experimentation of the Universidade Federal de Ouro Preto, Brazil (protocol no. 2013/26). The animals were kept in a $12 \mathrm{~h}$ day/night cycle, temperature $22 \pm 2{ }^{\circ} \mathrm{C}$, standard diet and water ad libitum. 


\subsubsection{Preparation of biological samples and validation parameters}

Benznidazole (BZ) was used as the internal standard (IS) because of its high purity, chemical stability, similar solubility in methanol and appropriate retention time compared to Lyso-7. The calibration standards to quantify Lyso-7 in biological matrices were made by preparing stock solutions of Lyso-7 $(1000 \mu \mathrm{g} / \mathrm{ml})$ and BZ (500 $\mu \mathrm{g} / \mathrm{ml})$ dissolved in ethyl acetate/methanol $(80: 20 \mathrm{v} / \mathrm{v})$. The working solutions were prepared via serial dilution of the stock solution at final concentrations of $0.1,1.0,2.5$, $5.0,10,25,50,75$ and $100 \mu \mathrm{g} / \mathrm{ml}$ and were used to prepare calibration curves. The linearity was evaluated with calibration standards $(n=6)$ over the concentration range $0.1-10 \mu \mathrm{g} / \mathrm{ml}$. Calibration curves were constructed using peak area ratios (Lyso-7/IS) versus analyte concentrations. After blood sampling from anesthetized mice (xylazine $7.5 \mathrm{mg} / \mathrm{kg}$; ketamine $60 \mathrm{mg} / \mathrm{kg}$ ), the plasma was separated, aliquoted and stored at $-80{ }^{\circ} \mathrm{C}$ until analysis, as previously described [21]. Thawed pieces of liver (200 mg) or weighed whole heart, spleen, lung and kidney were placed in a round-bottom flask, homogenized (1 min) with $1 \mathrm{ml}$ of phosphate buffer ( $\mathrm{pH} 6.5)$ in an ultrasonic processor with titanium probe (Vibra cell ${ }^{\mathrm{TM}}$ VC750, $300 \mathrm{~W}$ ). The tissue homogenates were then stored at $-80^{\circ} \mathrm{C}$ until analysis [21].

To determine the percentage of recovery of the method the tissue samples of mice (drug-free) were used as blanks, following FDA guidelines for validation of bioanalytical methods [22]. The blank mice plasma $(80 \mu \mathrm{l})$ or tissue homogenate $(80 \mu \mathrm{l})$ was spiked with Lyso-7 solution $(10 \mu \mathrm{l})$ plus $10 \mu \mathrm{l}$ of internal standard solution (BZ $500 \mu \mathrm{g} / \mathrm{ml}$ ). Two methods of plasma extraction were compared: protein precipitation (PP) with methanol and acetonitrile and liquid-liquid extraction (LLE) with ethyl acetate. Furthermore, parameters that influenced the recovery of the analyte and of the IS were analyzed, such as the solvent volume (300, 500 and $1000 \mu \mathrm{l})$ and the time of mixing the solvent with the sample (1-10 min). When the solid tissue samples were used (60-200 mg), ethyl acetate, hexane and diethyl ether were tested ( $1 \mathrm{ml}$ ), by mixing them for $10 \mathrm{~min}$ on vortex once or twice and extracted as previously reported by Oliveira et al. [21]. Briefly, the tubes containing real samples ( $80 \mu \mathrm{l}$ plasma $+10 \mu \mathrm{l}$ IS) or quality control $(80 \mu \mathrm{l}$ plasma $+10 \mu \mathrm{l}$ IS $+10 \mu$ l Lyso-7 working solution) samples were mixed with the corresponding amount of solvent at different times and centrifuged at $900 \times \mathrm{g}$ during $10 \mathrm{~min}$ The resulting upper organic layers were pooled, filtered with $0.45 \mu \mathrm{m}$ filters (Millipore, USA) and evaporated to dryness in a nitrogen-stream apparatus (TE-019 Concentrator/Tecnal, Brazil). Each dried sample was then reconstituted in $100 \mu \mathrm{l}$ of the mobile phase and injected $(25 \mu \mathrm{l})$ in the HPLC system.

Specificity of the bioanalytical method was evaluated by comparing the chromatograms of blank mouse tissues ( six different batches) to ensure no interference from biological samples at the retention time for IS and Lyso-7, respectively. Calibration curves were constructed and further analyzed following FDA criteria [22]. The low $(0.25 \mu \mathrm{g} / \mathrm{ml})$, medium $(2.5 \mu \mathrm{g} / \mathrm{ml})$ and high $(7.5 \mu \mathrm{g} / \mathrm{ml})$ analyte concentrations $(n=6)$ were used in precision and intra-batch accuracy determination at three different days for the biological samples. To evaluate the method sensitivity, lowest limit of quantification (LOQ) and limit of detection (LOD) were determined for Lyso-7. Analyte stability in the plasma, liver, heart, spleen, lung and kidney was determined $(n=6)$ under the following conditions: (1) determination of Lyso-7 in tissues through 3 freeze-thaw cycles; (2) Lyso-7 in tissues at room temperature for $4 \mathrm{~h}$ (short-term); and (3) Lyso-7 post-preparative stability into autosampler under $24 \mathrm{~h}$ storage.

\subsubsection{Pharmacokinetic and biodistribution studies}

The drug pharmacokinetic and biodistribution were determined in five organs (heart, liver, spleen, lung and kidney) in healthy mice using the bioanalytical method developed herein. The pharmacokinetic study was carried out with free Lyso-7 and Lyso-7-loaded PLA NC at the dose of 1.6 and $2.2 \mathrm{mg} / \mathrm{kg}$. The free Lyso-7 solution for intravenous (iv) injection was prepared dissolving $2 \mathrm{mg}$ of Lyso-7 in $20 \mu \mathrm{l}$ of DMSO, $20 \mu \mathrm{l}$ of Tween ${ }^{\circledR} 80,380 \mu \mathrm{l}$ of DMA and $580 \mu \mathrm{l}$ of PEG 300 . This solution was mixed for $10 \mathrm{~min}$ and then appropriately diluted in isotonic glucose to obtain $0.5 \mathrm{mg} / \mathrm{ml}$ of Lyso-7. The Lyso-7 iv solution and the $0.5 \mathrm{mg} / \mathrm{ml}$ Lyso-7 PLA NC suspension were passed through a $0.8 \mu \mathrm{m}$ sterile filter before appropriate dilution to allow intravenous injection in mice $(n=6)$ of the doses established. After each time interval, 5, 20, 40, 60, 120, 180 and $360 \mathrm{~min}$, blood samples (100-150 $\mu \mathrm{l})$ were collected in heparinized tubes and centrifuged for $15 \mathrm{~min}(400 \times \mathrm{g})$ to separate the plasma. Plasma $(80 \mu \mathrm{l})$ was spiked with $10 \mu \mathrm{l}$ of IS solution. Exceptionally after administration of the free Lyso-7 solution, four animals were euthanized at in each time interval of 40,60,120 and $180 \mathrm{~min}$ and total blood was collected by cardiac puncture in order to obtain a higher volume of plasma samples, because in those cases the amount of Lyso-7 assayed was lower than the quantification limit. The plasma samples were subsequently extracted using the method described above.

Lyso-7 distribution in organs (heart, liver, spleen, lung and kidney) was determined after intravenous administration of both formulations. Mice $(n=4)$ were euthanized at 10,30 and 60 min after $i v$ administration of Lyso-7 single dose $(1.6 \mathrm{mg} / \mathrm{kg}$ ) for both tests. The organs were collected and quickly washed with cold saline to remove blood excess and blotted with filter paper before weighing [21]. The analyses of the biological samples and quality control samples were performed within 12-24 h after sample collection.

In another experiment, the blood was removed from the organs using perfusion with saline before organ collection. This procedure allows the Lyso-7 concentration in each organ to be determined without the influence of blood flow. A single dose of $1.6 \mathrm{mg} / \mathrm{kg}$ of Lyso-7 PLA NC and free Lyso-7 was intravenously administrated to mice $(n=4)$ and $10 \mathrm{~min}$ after, the mice were euthanized and the organs perfused. The perfused heart and liver were processed as described above.

\subsubsection{Pharmacokinetics and statistical analysis}

The pharmacokinetic parameters for Lyso-7 were determined by means of non-compartmental approach based on the plasmaconcentration profiles of Lyso-7 in both formulations after bolus intravenous administration. The area under the curve $\left(\mathrm{AUC}_{0-\mathrm{t}}\right)$ and the area under the first-moment curve $\left(\mathrm{AUMC}_{0-\mathrm{t}}\right)$, where $\mathrm{t}$ is the last sampling time, were calculated by the linear trapezoidal rule method. The area under the curve extrapolated to infinity $\left(\mathrm{AUC}_{0-\infty}\right)$ was obtained by the equation $\mathrm{AUC}_{0-\infty}=\mathrm{AUC}_{0-\mathrm{t}}+\mathrm{C}_{\mathrm{p}} / k_{\mathrm{e}}$, where $\mathrm{C}_{\mathrm{p}}$ is the last measurable concentration and $k_{\mathrm{e}}$ is the elimination rate constant. The $\mathrm{AUMC}_{0-\infty}$ was calculated as AUMC $0-\mathrm{t}+\left(\mathrm{C}_{\mathrm{p}} \times \mathrm{t} / k_{\mathrm{e}}\right)+\left(\mathrm{C}_{\mathrm{p}} / k_{\mathrm{e}}^{2}\right)$. The clearance $(\mathrm{Cl})$ was calculated as Dose / AUC and the apparent volume of distribution $\left(\mathrm{V}_{\mathrm{d}}\right)$ as MRT $\times \mathrm{Cl}$, where MRT is the mean residence time obtained by $\mathrm{AUMC}_{0-\infty} / \mathrm{AUC}_{0-\infty}$. The slope of linear regression of the logtransformed concentration versus time in the terminal phase was used to obtain $k_{\mathrm{e}}$. All data analysis was performed with PKSolver ${ }^{\circledR}$ add-in software (Microsoft ${ }^{\circledR}$ Excel) [23]. Mean \pm standard errors (SE) were plotted in plasma $\times$ concentration curves. Student's $t$-test was used to calculate differences between mean values obtained for some of the pharmacokinetic parameters in each experimental group (Graph Pad Prism 5.01 software).

\section{Results}

Biodegradable PLA NC loaded with Lyso-7 were successfully obtained by precipitation of the preformed polymer followed by the solvent displacement method [16], which resulted in a colloidal suspension with a mean particle size of $273 \mathrm{~nm}$, polydispersity indexes lower than 0.3 and $\zeta$ potential of $-39.7 \pm 6.1 \mathrm{mV}$. The drug payload was 6 $7 \% \mathrm{wt} / \mathrm{wt}$ and the encapsulation efficiency of Lyso-7 was as high as $83 \%$ at $0.42 \mathrm{mg} / \mathrm{ml}$ Lyso-7 concentration in the final formulation (Table 1). Higher concentrations of Lyso-7 seemed to saturate the loading capacity of these NCs and the drug appeared as a precipitate upon storage for a short period of time, reducing the encapsulation efficiency (Table 1). Loading of Lyso-7 had no influence on the surface charge of the PLA NC $(p>0.05)$, as shown by zeta potential measurements, 
Table 1

Physicochemical characterization of Lyso-7 nanocapsules.

\begin{tabular}{|c|c|c|c|c|c|c|c|c|}
\hline NC & $\begin{array}{l}\text { Lyso-7 feed } \\
(\mathrm{mg} / \mathrm{ml})\end{array}$ & $\begin{array}{l}\text { Mean diameter }{ }^{a} \pm \text { SD } \\
\text { QELS }(\mathrm{nm})\end{array}$ & $\begin{array}{l}\text { Mean polydispersion } \\
\text { index }^{b}\end{array}$ & $\begin{array}{l}\text { Mean diameter } \pm \text { SD } \\
\text { AFM }(\mathrm{nm})\end{array}$ & Zeta potential $^{a} \pm \mathrm{SD}(\mathrm{mV})$ & $\% \mathrm{EE}$ & $\begin{array}{l}\text { \% Payload } \\
\text { (drug/polymer) }\end{array}$ & $\begin{array}{l}\text { Lyso-7 final } \\
(\mathrm{mg} / \mathrm{ml})\end{array}$ \\
\hline PLA-NC & - & $201 \pm 5$ & 0.140 & $246 \pm 42$ & $-46 \pm 5$ & - & - & \\
\hline Lyso-7 NC & 0.5 & $274 \pm 1$ & 0.177 & $281 \pm 38$ & $-40 \pm 5$ & 83 & $6.9 \%(w t / w t)$ & 0.42 \\
\hline Lyso-7 NC & 1.0 & $286 \pm 3$ & 0.290 & ND & ND & 37 & $6.2 \%(w t / w t)$ & 0.37 \\
\hline
\end{tabular}

EE: encapsulation efficiency as defined in the methodology section; AFM: atomic force microscopy; QELS: quasi-elastic light scattering.

${ }^{a}$ Means \pm standard deviation ( $\mathrm{n}=3$ formulation batches).

${ }^{b}$ Mean polydispersity index of nanoparticle population measurements ( 3 batches) just after preparation without any purification.

which suggests that Lyso-7 is mainly associated with the oily core. The size of the NC increased upon loading with Lyso-7, which is also in agreement with Lyso-7 being located in the NC core. The mean $z$-average hydrodynamic diameter obtained by QELS analysis, SEM and AFM diameter measurements were similar, in the range of 200-280 nm (Table 1 and Figs. 2 and 3). The mass ratios between Lyso- 7 and PLA polymer were 0.07 and $0.06 \mathrm{wt} / \mathrm{wt}$ at the Lyso- 7 initial concentrations of 0.5 and $1.0 \mathrm{mg} / \mathrm{ml}$ of feeding, respectively (Table 1 ).

The morphology and sizes of unloaded and Lyso-7 loaded NC were also determined by AFM. The images showed the presence of welldefined spherical structures with a fairly homogenous surface, as shown in Fig. 2A, phase image of 2B and on Fig. 2D, in a threedimensional view. Analysis of the topographical profile indicated a diameter/height ratio of 1.3 , which is consistent with a fluid inner structure of these Lyso-7 NC (Fig. 2C), as previously reported for other drug-loaded NC $[17,24]$. Furthermore, AFM phase images show differences in the texture and stiffness of $\mathrm{NC}$ between the core and the outer layer (Fig. 2B). Micelles of reduced size (12-25 nm) were also observed in the AFM images (Fig. 2B) and are in agreement with poloxamer 188 micellar diameters (14 nm) [25].

SEM images show Lyso-7 NC (Fig. 3) monodisperse in size, which corroborate the QELS and AFM analyses. Furthermore, although the samples were analyzed under very low energy electron beam and under thin coating with gold ( $100 \AA$ ) fast deformation of the spheres upon heating was observed (Fig. $3 \mathrm{~A}$ ), most likely due to the liquid nature of the core and thin polymeric membrane of the NC. PLA has low glass transition temperature $\left(\mathrm{T}_{\mathrm{g}} 50-84^{\circ} \mathrm{C}\right)$. Therefore, obtaining SEM images of Lyso-7 PLA NC is a challenging task, as the NC were found to melt and shrink upon heating with the electron beam. Shrinking of the polymeric wall of the NC can be seen on Fig. 3A and B.

Hemolytic activity was determined to evaluate the in vitro toxicity towards RBC of the free Lyso-7 and Lyso-7 in NC, considering that these formulations may be used for intravenous administration (Fig. 4). The percentage of hemolysis observed was 14\% (free Lyso-7), 8\% (Lyso-7 loaded PLA NC) and 2\% (blank PLA NC) at the high doses. The mean hemolytic activity of Lyso-7 in solution was significantly higher $(p<0.05)$ than the Lyso-7 PLA NC (1.6-fold lower).

The chromatographic method developed to quantify Lyso-7 in the formulations showed a retention time of $4.80 \mathrm{~min}$ for Lyso-7 and good selectivity in the presence of NC excipients, as shown in the chromatograms (Fig. ST1). The method is linear in the concentration range of $500-100,000 \mathrm{ng} / \mathrm{ml}$. The slope, intercept and the correlation coefficient were 119817 (a), 8229.4 (b) and $0.9997\left(r^{2}\right)$, respectively. The method was entirely validated according to the current guidelines. The results are presented in the Table ST2 of the Supplementary material, which shows that all precision and accuracy data were within the recommended values [22]. The LOD and LOQ values were $150 \mathrm{ng} / \mathrm{ml}$ and $450 \mathrm{ng} / \mathrm{ml}$, respectively.

The Lyso-7 dissolution profile and the release profile of Lyso-7 PLANC are shown in Fig. 5. Within $360 \mathrm{~min}$ ( $6 \mathrm{~h}$ ) of NC dispersion into the release medium, a rapid initial burst of Lyso-7 occurred, releasing $47 \%$ of Lyso-7 from the NC. After that, between 360 and 720 min the release from the NC was slow and sustained, reaching $58 \%$ of release, compared to $82 \%$ of dissolution of the free Lyso-7 in the medium. The time required to release $50 \%$ of the encapsulated Lyso-7 was 427 min versus
32 min for Lyso-7 to reach 50\% dissolution in PBS medium at pH 7.4. The quantitative interpretation of the values obtained in the dissolution/release tests is facilitated by the use of mathematical models [26].

The Lyso-7 release kinetics was fitted using Higuchi, zero-order, first-order and Korsmeyer-Peppas models. Table 2 shows the regression coefficients $\left(r^{2}\right)$, the release constants $\left(k_{\mathrm{h}}, k_{0}, k_{1}\right.$ and $k$ values), and the $n$ value, which is the release exponent calculated using the Korsmeyer-Peppas model [26]. The Lyso-7 release kinetics was best described by the Korsmeyer-Peppas model, which provided the highest regression coefficient.

In the development of a bioanalytical method to quantify Lyso-7 in biological samples, the protein precipitation (PP) with acetonitrile $(1 \mathrm{ml})$ procedure was chosen to extract Lyso-7 from plasma samples, because it provides very clean chromatograms and a higher percentage of recovery (97.46\%) than the liquid-liquid extraction (LLE) procedure using ethyl acetate (24.3-84.8\%). On the contrary, higher recovery values for Lyso-7 and IS (approximately 100\%) from the heart, liver, spleen, lung and kidney samples were obtained via extraction with ethyl acetate, as shown in Table ST3 (Supplementary data). Thus, the extraction procedure was performed for all tissues with three portions of $500 \mu \mathrm{l}$ of ethyl acetate. No interferences were found from the biological matrices or from assay reagents, as shown in plasma, heart and liver chromatograms (Fig. ST1 B, C and D, respectively). The retention times for Lyso-7 (4.8 min) and IS (1.8 $\mathrm{min}$ ) and the resolution in our chromatographic conditions were considered appropriate (Fig. ST1). The method was linear in the range of $100-10,000 \mathrm{ng} / \mathrm{ml}$ in all matrices. The LOQ and LOD were $100 \mathrm{ng} / \mathrm{ml}$ and $50 \mathrm{ng} / \mathrm{ml}$, respectively, in all biological matrices. Standard curves, equations (means, $n=6$ ), the correlation coefficients $\left(r^{2}\right)$, and the between-day, intra-day precision, accuracy and stability assays are shown on Tables ST4, ST5 and ST6, respectively (Supplementary material)

\subsection{Pharmacokinetic and biodistribution studies}

The intravenous administration of $2.2 \mathrm{mg} / \mathrm{kg}$ of free Lyso- 7 in solution in mice led to immediate death of all animals $(n=6)$, indicating that intravenous $\mathrm{LD}_{50}$ of free Lyso-7 is lower than $2.2 \mathrm{mg} / \mathrm{kg}$ in mice. The same concentration of excipients used to prepare Lyso-7 in solution was administered and induced no deaths or adverse effects within $24 \mathrm{~h}$. Therefore, we evaluated the plasma profile of the free Lyso-7 administering a lower dose $(1.6 \mathrm{mg} / \mathrm{kg})$, which induced no deaths in mice, after a preliminary dose screening with no observable adverse effect level (NOAEL) in acute toxicity test (data not shown), according to OECD (Organization for Economic Co-Operation and Development) guidelines. The doses of 1.6 and $2.2 \mathrm{mg} / \mathrm{kg}$ of Lyso-7 loaded in PLA NC were administered $i v$ to the animals and were found to induce no deaths or observable toxic effects. Lyso-7 association with NC increased the $\mathrm{LD}_{50}$ of Lyso-7 and produced no signals of general toxicity observable during this study.

Fig. 6 shows the curves of Lyso-7 concentration versus time in the blood upon iv administration of Lyso-7 in solution and Lyso-7loaded in PLA-NC. The pharmacokinetic profiles show that the Lyso-7 plasma concentration was significantly higher $(p<0.001)$ for NC than for the solution until $1 \mathrm{~h}$ after administration. After 3 hour postadministration of free Lyso-7, its plasma concentration was below the 

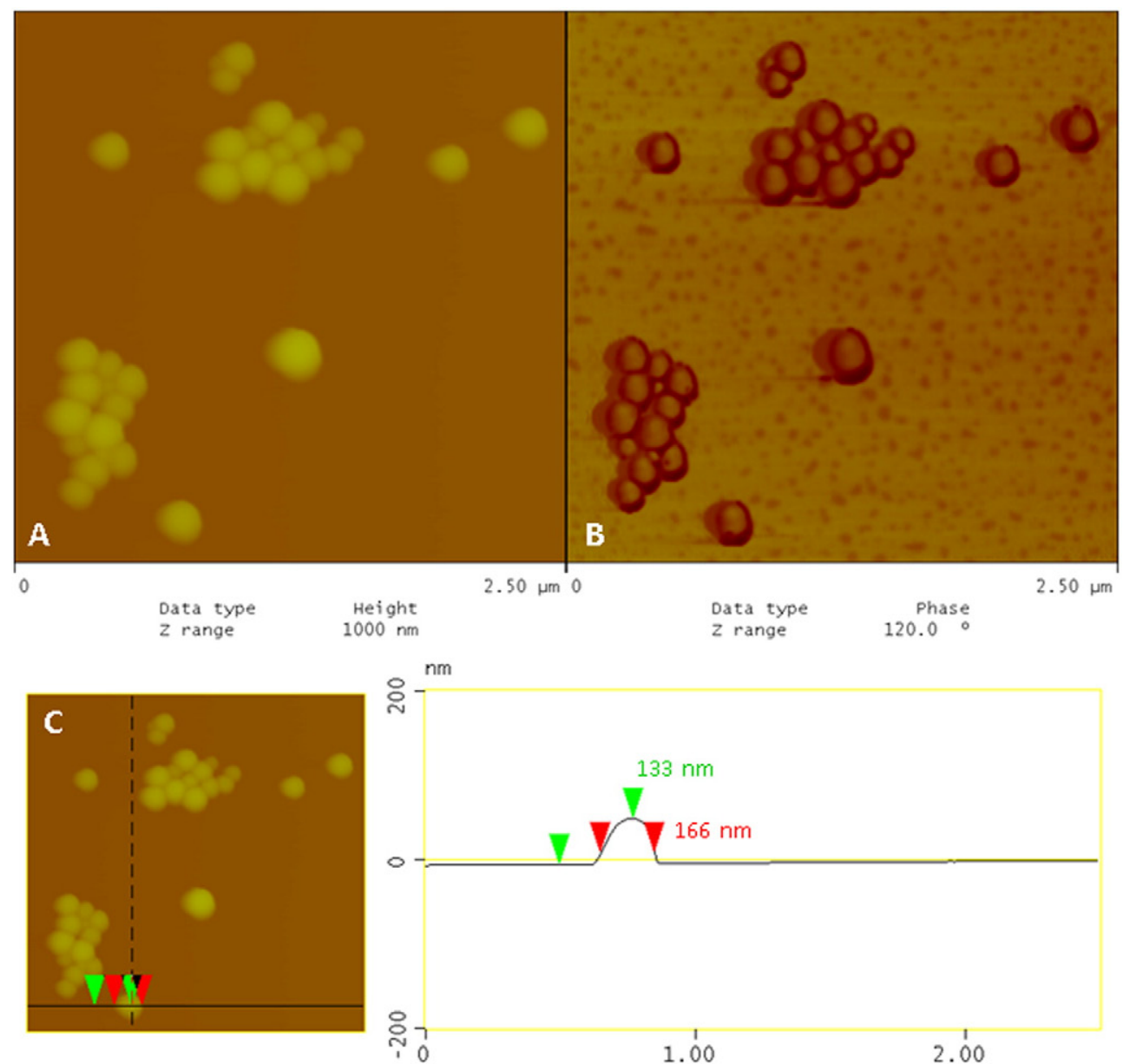

$\mu \mathrm{m}$

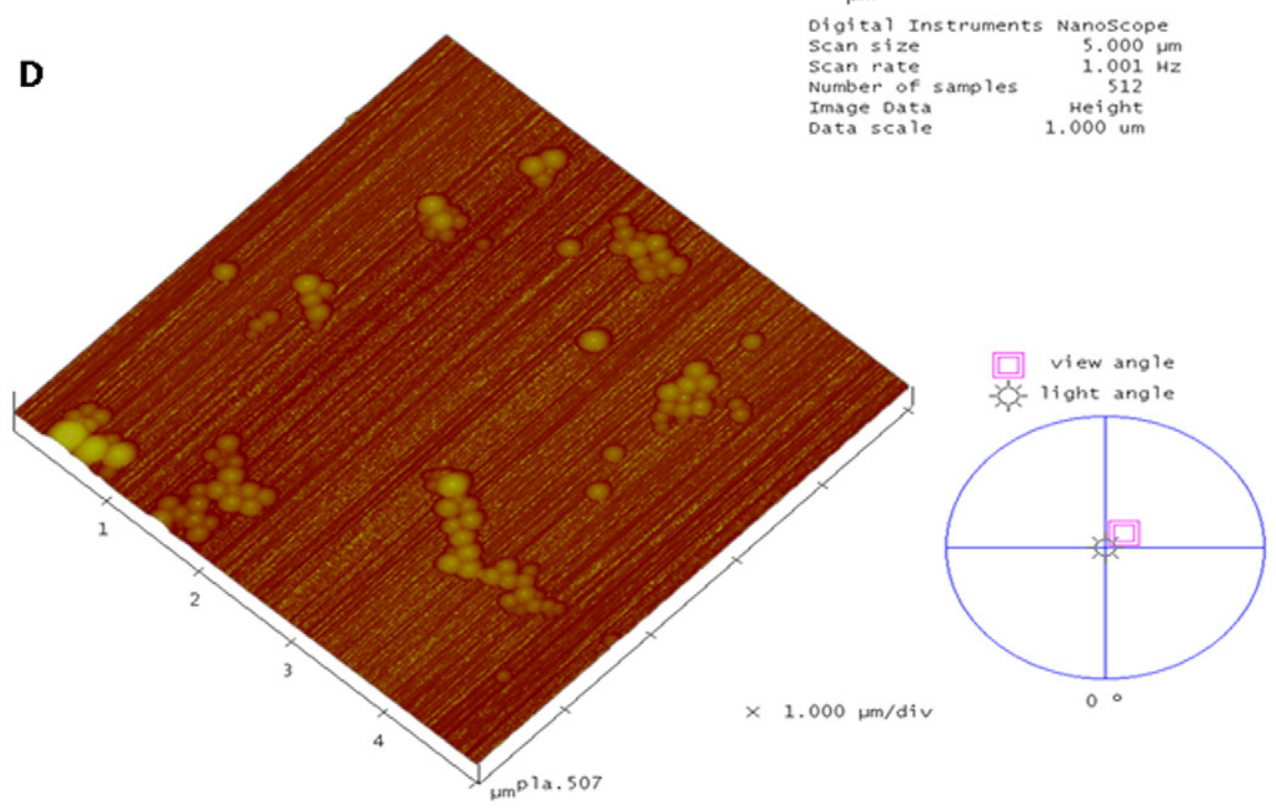

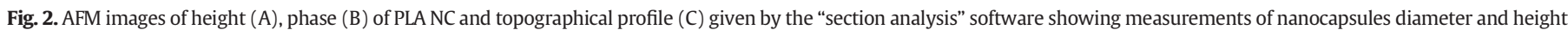
Scan size: $2.5 \times 2.5 \mu \mathrm{m}$. (D) AFM image giving a three-dimensional view of PLA NC containing Lyso-7 ( $0.5 \mathrm{mg} / \mathrm{ml}) \mathrm{spread}$ on mica. Scan size: $5 \times 5 \mu \mathrm{m}$.

detection limit by the HPLC method. Higher concentrations were recovered from plasma with Lyso-7 associated with NC even after $6 \mathrm{~h}$. The mean pharmacokinetic parameters are summarized in Table 3. Higher body exposure to Lyso-7 with NC formulation was further confirmed by the increase in the area under the curve $\left(\mathrm{AUC}_{0-\mathrm{t}}\right)$ (Table 3$)$. The
$\mathrm{AUC}_{0-\mathrm{t}}$ and $\mathrm{AUC}_{0-\infty}$ values after intravenous administration of free Lyso-7 were 14-fold and 12-fold lower than Lyso-7-loaded PLA-NC, respectively. Furthermore, the Lyso-7-loaded PLA-NC increased considerably the MRT by 2-fold while plasma half-life was increased 1.4-times. Plasma clearance $(\mathrm{Cl})$ was reduced 13 -fold, as well as the 

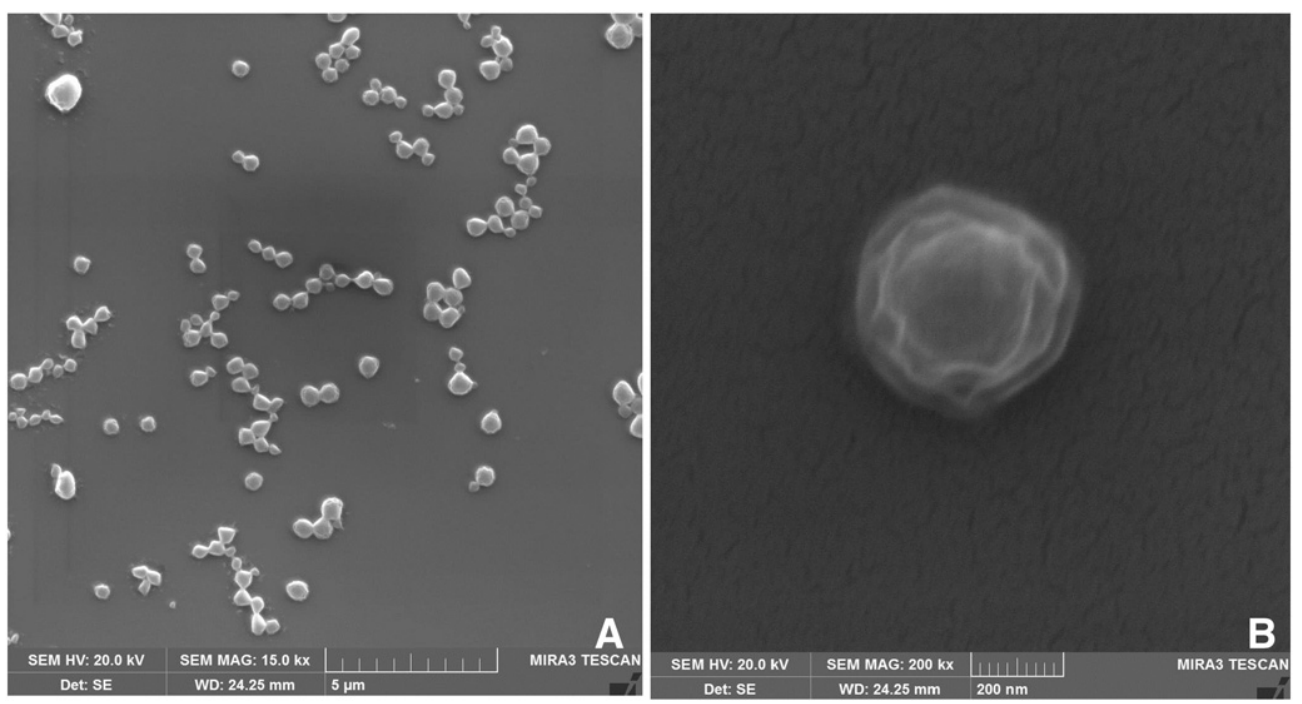

Fig. 3. SEM images of Lyso-7 PLA NC (A) and nanocapsule detail (B). Images were obtained at $20 \mathrm{kV}$ after sample coating (100 Å) with gold.

apparent distribution volume $\left(\mathrm{V}_{\mathrm{d}}\right)$ (10-fold) and the elimination rate $\left(k_{\mathrm{e}}\right)$ (1.3-fold).

The Lyso-7 distribution in the heart, liver, spleen, lung and kidney samples is shown in Fig. 7, as the concentration of Lyso-7 in $\mu \mathrm{g}$ per $\mathrm{g}$ of tissue after 10, 30 and 60 min post-administration of Lyso-7. After $10 \mathrm{~min}$, the Lyso-7 concentrations in all tissues were significantly higher $(p<0.05)$ when Lyso-7 was administrated in NC formulation than when it was administrated in solution. The AUC increased significantly $(p<0.05)$ in the heart (3.6-fold), liver (1.8-fold), spleen (2.3-fold), lung (2.8-fold) and kidney (2-fold) for Lyso-7 in NC compared to solution (Fig. 7). Furthermore, there were no significant differences between the Lyso-7 levels in the heart and liver, with or without vascular perfusion of the organs with saline (Table 4), indicating that the increase in Lyso-7 concentration after NC administration in these tissues was not due to alterations in the blood flow, neither in the amount of blood in the vessels in these tissues after necropsy.

\section{Discussion}

Lyso-7 was efficiently encapsulated in the oily core of PLA NC, as expected due to its high lipophilicity $(\log p=5.62)$. Suitable encapsulation efficiency (EE) was achieved ( $83 \%)$ with an encapsulation process that requires no further purification steps, in agreement with EE reported in previous studies (40-100\%) for PLA NC prepared by the nanoprecipitation method [27]. In vivo studies showed that Lyso-7 has high potency within this class of drugs ( $3 \mathrm{mg} / \mathrm{kg}$ ) compared to other anti-inflammatory drugs, indomethacin ( $10 \mathrm{mg} / \mathrm{kg})$, and TZDs,

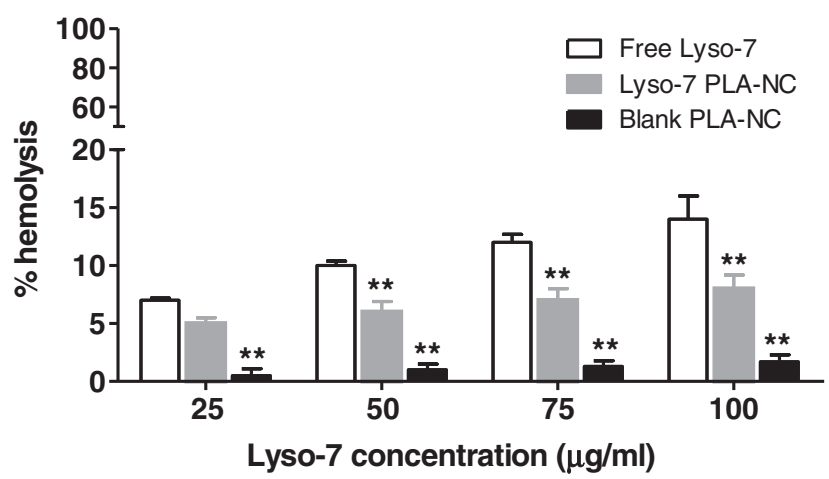

Fig. 4. Percentage of hemolysis upon incubation with free Lyso-7, blank PLA-NC and Lyso7-loaded PLA-NC. pioglitazone $(50 \mathrm{mg} / \mathrm{kg}$ ) [10,11], which enables the use of such Lyso7-NC formulation even though the drug payload was not very high (7\% wt/wt). However, lower payloads of $0.6-1.4 \%$ and $1.3-3 \% \mathrm{wt} / \mathrm{wt}$ were recently reported for genistein PLA NC [28] and hydrophobic phtalocyanine in PLA NC, respectively [17]. Furthermore, similar payload of $4-6 \% \mathrm{wt} / \mathrm{wt}$ was obtained with docetaxel in PLGA NC [29]. The negative zeta potential of the NC can be attributed to the polarization of the ionic groups located at their surface, mainly the phosphatidic acid of the lecithin used in the formulation (Epikuron170®), as discussed previously [30]. Loading with Lyso-7 produced no significant modification on the zeta potential of the NC, which suggests that at concentrations up to $0.5 \mathrm{mg} / \mathrm{ml}$ of Lyso-7 is mainly located in the oily core.

The AFM images of Lyso-7 NC (Fig. 2C) evidenced the deformable structure of this vesicular carrier with a diameter/height ratio higher than 1.3. Another type of evidence from AFM images is the difference in contrast between the core and the corona observed in phase images (Fig. 2B), as already reported for NC systems [17,24]. The core appears brighter and surrounded by a darker rim, indicating that the texture and stiffness of the NC core are different from the NC wall, as observed clearly in Fig. 2B (phase image). The difference in mean diameter obtained by AFM in comparison with QELS could be attributed to two artifacts associated with AFM analysis as previously discussed by other authors, namely flattening of the NC [24] and overestimated lateral dimensions related to the geometry of the AFM tip [31]. SEM images show enlarged NC diameters (Fig. 3A), of approximately $300 \mathrm{~nm}$, that could be attributed to the melt, shrinkage and deformation of NC

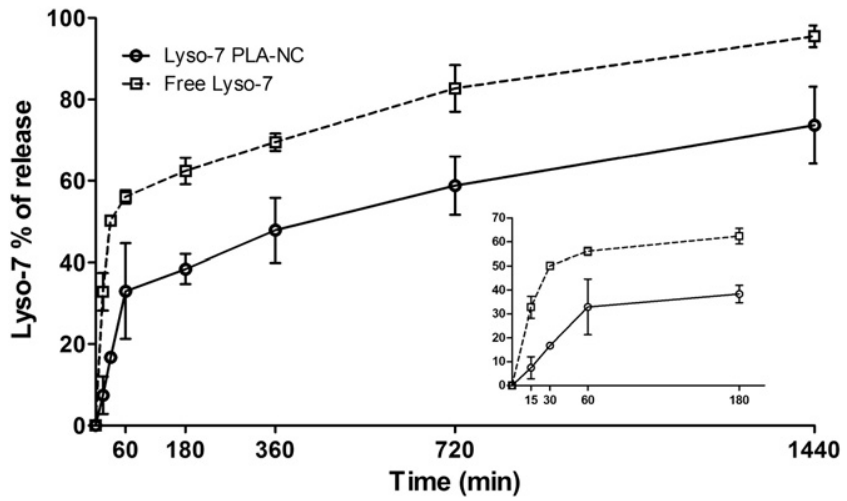

Fig. 5. Profiles of in vitro Lyso-7 free dissolution kinetics and Lyso-7 release kinetics from PLA-NC in PBS at pH 7.4. The insert shows the first $180 \mathrm{~min}$ in detail. 
Table 2

Mathematical modeling of dissolution/release data of free Lyso-7 and Lyso-7 loaded PLANC.

\begin{tabular}{llll}
\hline Mathematical model & & Free Lyso-7 & Lyso-7 PLA-NC \\
\hline Higuchi & $k_{\mathrm{h}}$ & $0.0745 \mathrm{~min}^{-1 / 2}$ & 0.0481 \\
& $r^{2}$ & 0.7765 & 0.8573 \\
Zero-order & $k_{0}$ & $0.0195 \mathrm{~min}^{-1}$ & 0.0109 \\
First-order & $r^{2}$ & 0.6158 & 0.5056 \\
Kosmeyer-Peppas & $k_{1}$ & $0.0404 \mathrm{~min}^{-1}$ & 0.1209 \\
& $r^{2}$ & $0.9562 \mathrm{~min}^{-\mathrm{n}}$ & 0.6810 \\
& $k$ & $0.1717 \mathrm{~min}^{2}$ & 0.0639 \\
& $n$ & 0.1920 & 0.3952 \\
\hline
\end{tabular}

under electron beam heating (Fig. 3B). Benita and co-workers observed the same effects on PLGA NC analyzed by SEM [29]. These results indicate that evaluation of the NC diameters must be done by two or more complementary sizing techniques considering the limitations of each one, as previously discussed [31]. Altogether, the physicochemical results indicate that Lyso-7 is associated to the oily core and that a polymeric wall surrounds and separates the drug from the external medium.

The observations described above were in agreement with the Lyso$7 \mathrm{NC}$ reduced in vitro toxicity against RBC compared to free drug. It occurred likely by delaying the Lyso-7 release from the NC and reducing the fraction of drug in contact with RBC. NC without drug or loaded with Lyso-7 exhibited very low hemotoxicity in our studies and they can be considered non-hemolytic, in accordance with recently published work [32]. In our pharmacokinetic study in mice, the estimated plasma concentration at time zero of free Lyso-7 was $35.5 \mu \mathrm{g} / \mathrm{ml}$, 3fold lower than the concentration of $100 \mu \mathrm{g} / \mathrm{ml}$ that caused $14 \%$ of hemolysis by free Lyso-7 in solution and 6\% of hemolysis by Lyso-7loaded NC, which are both acceptable values. Thus, even plasma concentrations of free Lyso-7 higher than $100 \mu \mathrm{g} / \mathrm{ml}$ seem to be safe for parenteral administration in terms of toxicity against RBC and the nanoencapsulation improves safety for intravenous administration of Lyso-7. Furthermore, the release rate of Lyso-7 from NC was reduced in comparison with the dissolution rate of Lyso-7 in buffered saline, which proves that NC is an efficient carrier to retain and prolong Lyso7 release in the blood.

The analysis of mathematical modeling of dissolution/release data suggests that the dissolution is better described by the first-order model $\left(r^{2}=0.9562\right)$ and Lyso-7 release from NC is better described by Korsmeyer-Peppas modeling $\left(r^{2}=0.9377\right)$, with a 4 -fold reduction of the dissolution rate constant (Table 2). The $n$ value, relative to Korsmeyer-Peppas model, indicates that the Lyso-7 has to diffuse

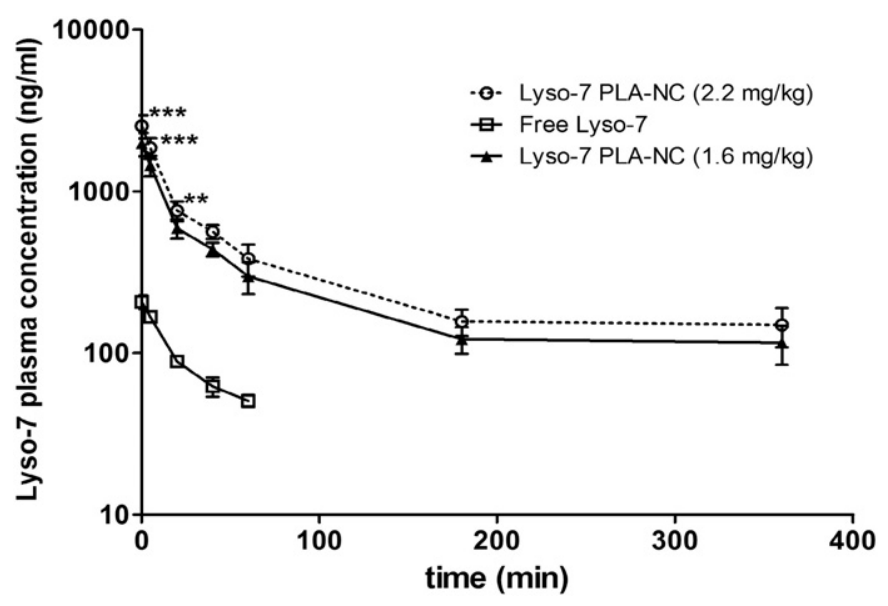

Fig. 6. Plasma concentration-time profiles after intravenous administration in mice of free Lyso-7 $(1.6 \mathrm{mg} / \mathrm{kg})$ and Lyso-7 in PLA-NC (1.6 and $2.2 \mathrm{mg} / \mathrm{kg})$ formulations. Mean $\pm \mathrm{SE}$, $n=6$; ${ }^{* * *} p<0.001,{ }^{* *} p<0.01$, using two-way ANOVA.
Table 3

Pharmacokinetics parameters of Lyso-7 after intravenous administration.

\begin{tabular}{lcc}
\hline Parameter & Lyso-7 free & Lyso-7 loaded in PLA-NC \\
\hline $\mathrm{AUC}_{[0-\mathrm{t}]}(\mu \mathrm{g} / \mathrm{ml} \times \mathrm{min})^{\mathrm{a}}$ & $5.45 \pm 0.65$ & $80.43 \pm 9.10^{*}$ \\
$\mathrm{AUC}_{[0-\infty]}(\mu \mathrm{g} / \mathrm{ml} \times \mathrm{min})$ & $5.73 \pm 1.05$ & $82.64 \pm 7.50^{*}$ \\
$\mathrm{Cl}(\mathrm{ml} / \mathrm{min})$ & $244.50 \pm 35.20$ & $18.37 \pm 2.13^{*}$ \\
$\mathrm{~V}_{\mathrm{d}}(\mathrm{ml})$ & $5943 \pm 1704$ & $584.90 \pm 34.03^{*}$ \\
$\mathrm{MRT}(\mathrm{min})$ & $27.57 \pm 3.47$ & $72.40 \pm 13.82^{*}$ \\
$k_{\mathrm{e}}(1 / \mathrm{min})$ & $0.042 \pm 0.008$ & $0.031 \pm 0.005^{* *}$ \\
$t_{1 / 2}(\mathrm{~min})$ & $16.40 \pm 1.40$ & $23.70 \pm 2.50^{*}$ \\
\hline
\end{tabular}

Data are expressed as means \pm relative standard deviation $(n=6)$. Administered dose: $1.6 \mathrm{mg} / \mathrm{kg}$.

a Time (t) was 60 min for Lyso-7 free and $360 \mathrm{~min}$ for Lyso-7 loaded in PLA-NC.

* $p<0.001$ compared to free drug.

** $p<0.01$ compared to free drug.

through the polymeric wall following Fickian diffusion, and the thickness of the polymeric wall can influence the diffusion rates [26].

Encapsulation led to reduced general toxicity of Lyso-7 upon iv administration, which was otherwise lethal at doses above $2 \mathrm{mg} / \mathrm{kg}$ (free Lyso-7). The cause of death provoked by $i v$ injection of $2 \mathrm{mg} / \mathrm{kg}$ of Lyso-7 in solution requires further investigation. However, our in vivo studies demonstrated that this toxicity could be reduced by association of Lyso-7 with the NC. It is difficult to determine the fraction of Lyso-7 that is not associated with the NC after $i v$ administration, however the NC most likely retained a significant fraction of Lyso-7 over time, which allowed the blood concentration to remain below the limit of toxicity. This may be a key to understanding the difference in toxicity between free Lyso-7 and the NC formulation.

No data concerning Lyso-7 quantification method have been reported to date. Thus, the development of analytical and bioanalytical methods is crucial for continuing research with this investigational drug. Both methods developed in the present study, analytical and bioanalytical, have shown to be selective, since Lyso-7 retention-time in the chromatograms was not significantly modified in the presence of the biological matrices or of the excipients of the NC formulation. Furthermore, no degradation peaks were observed in chromatograms obtained with multi-wavelength detection using photon diode array detector (data not shown), which indicates that the conditions used were suitable to maintain Lyso-7 chemical stability. The analytical method was sensitive, precise and accurate enough to allow routine analysis of Lyso-7 content associated with $\mathrm{NC}$ as well as the encapsulation efficiency.

The bioanalytical methods developed and validated herein with biological samples (PP for plasma samples and extraction with ethyl acetate for the heart, liver, spleen, lung and kidney samples) allow a fast, simple and cost-effective assay of the plasma and tissue samples. Furthermore, this method is sensitive in the sense that only small samples of plasma and tissues are required to enable pharmacokinetic and biodistribution studies to be performed ( $80 \mu \mathrm{l}$ and $200 \mathrm{mg}$, respectively). The selected internal standard (BZ) was appropriate because of its high recovery from biological matrices $(>95 \%$ ), good chromatographic separation from the analyte and similar solubility in the solvents used in the extraction procedure. The stability data analysis suggested that the biological samples containing Lyso-7 can be manipulated, frozen, thawed and refrozen without loss of its chemical integrity and purity in these matrices (complete data is available in Supplementary material). This method is a valuable contribution to better define pharmacokinetic profiles of this new substance and assess further preclinical investigations, such as pharmacokinetic/pharmacodynamic relationships and biodistribution studies in other animal models.

The pharmacokinetics analysis revealed that Lyso-7 elimination half-life was short in mice, approximately $17 \mathrm{~min}$. In order to be useful in diabetes, inflammatory cardiovascular disorders and in metabolic syndrome, a more sustained residence of Lyso-7 in the vascular compartment is desirable. In this sense, the increase in Lyso-7 plasma AUC and MRT and reduction in apparent volume of distribution provided 


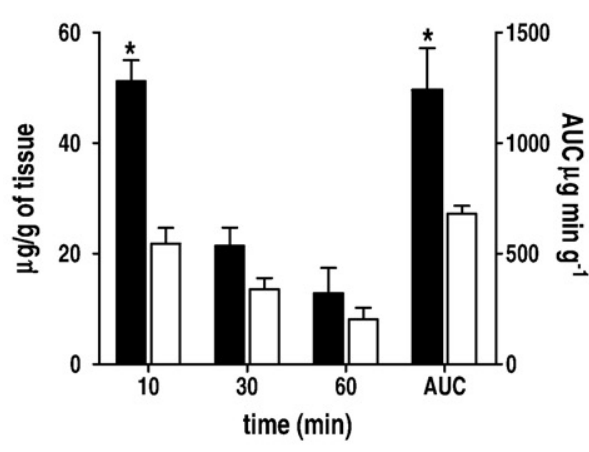

D - Lung

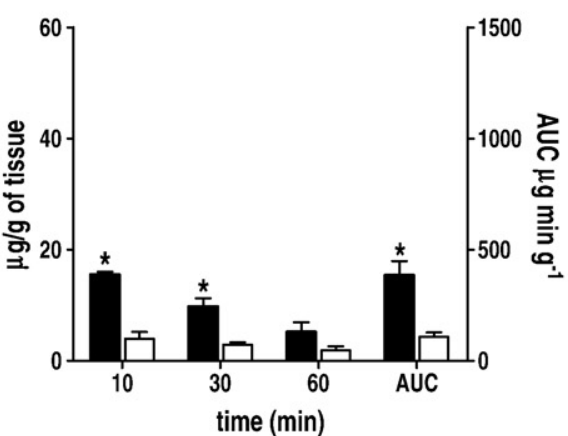

E - Kidney
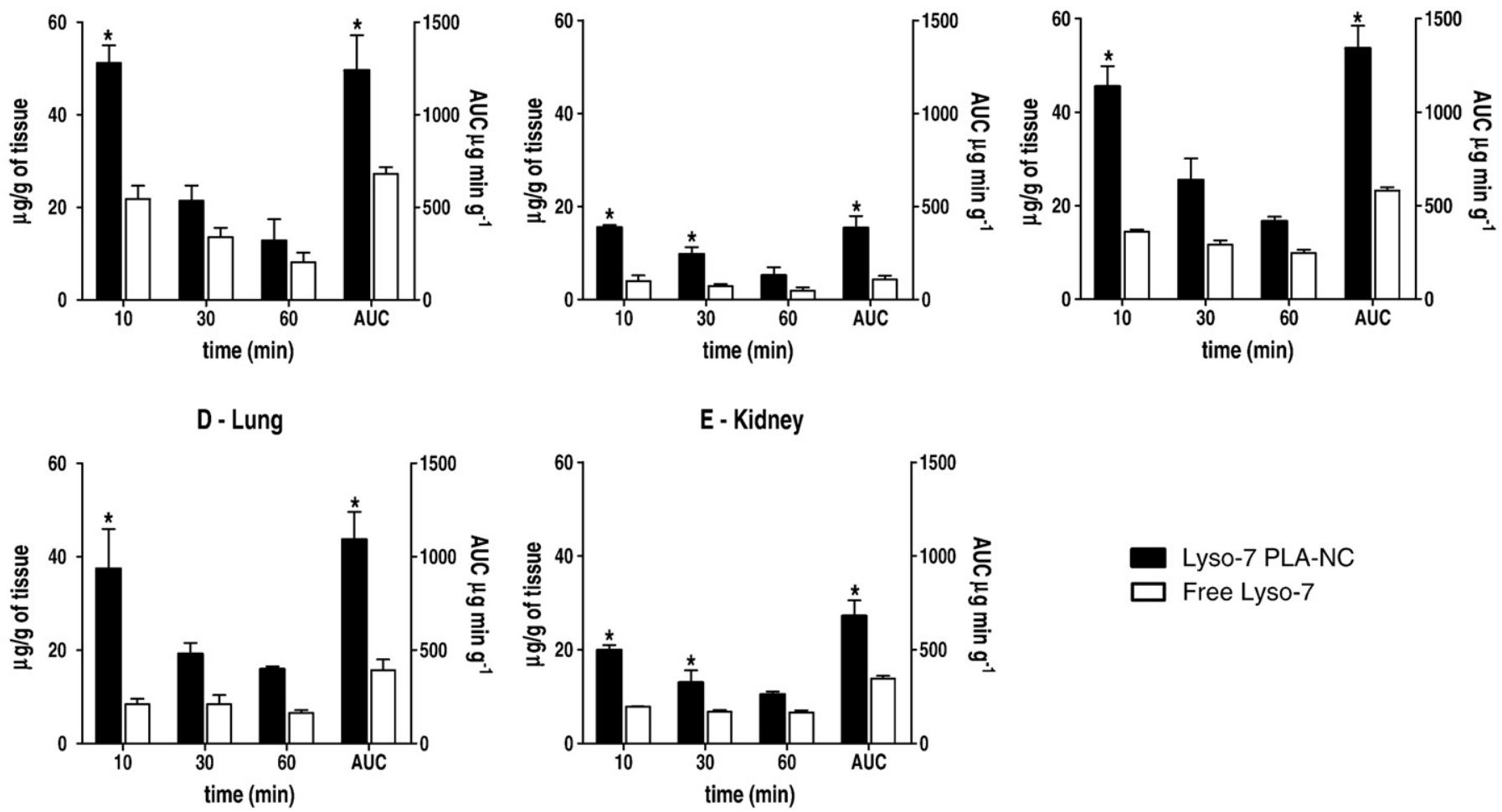

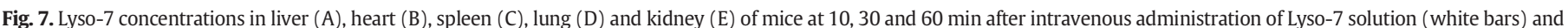

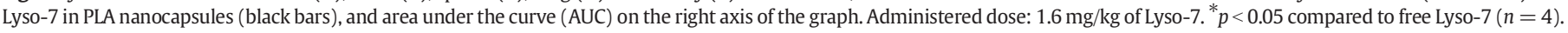

by the NC have beneficial effect. In this work, the ability of PLA NC to modify the plasmatic profile of Lyso-7 (Table 3) was demonstrated, as an increase in the plasma concentration was observed in the first 60 min after administration, as well as a 14-fold increase in the AUC. Our results are in agreement with those of Mosqueira et al., where the biodistribution of another hydrophobic drug, halofantrine, associated with a similar PLA NC formulation, was altered in a similar way in vivo, increasing the AUC by 6-fold [33]. Similar formulations of PLA NC loading lipophilic drugs also resulted in an increase of the lethal dose of the associated drug and reduced cardiac toxicity in the first $30 \mathrm{~min}$ after $i v$ administration [33,34]. Lyso-7 clearance was significantly reduced by associating this drug with polymeric NC, probably because its release was delayed in accordance with in vitro data.

In a previous work doses of $1 \mu \mathrm{M}(0.45 \mu \mathrm{g} / \mathrm{ml})$ of Lyso-7 were active in inhibiting COX-1 and COX-2 and $\mathrm{EC}_{50}$ of 10 and $50 \mu \mathrm{M}$ activated PPAR- $\alpha$, PPAR- $\beta / \delta$ or PPAR- $\gamma$ in vitro [10]. Thus, if we define the minimum effective concentration (MEC) in plasma for Lyso-7 to be $10 \mu \mathrm{M}$ $(4.48 \mu \mathrm{g} / \mathrm{ml})$ for both actions, then three half-lives will be necessary for the plasma concentration to be above the MEC for the intravenous dose of $1.6 \mathrm{mg} / \mathrm{kg}$. This corresponds to approximately 50 and $75 \mathrm{~min}$ after iv administration of free Lyso-7 and Lyso-7 NC, respectively, assuming $45 \mathrm{ml} / \mathrm{kg}$ as the mice plasma volume. The oral dose ( $3 \mathrm{mg} / \mathrm{kg}$ )

Table 4

Effect of organ perfusion with PBS on Lyso-7 tissue concentrations in heart and liver 10 min after Lyso-7 administration ( $\mu \mathrm{g} / \mathrm{g}$ of tissue).

\begin{tabular}{|c|c|c|c|c|}
\hline & \multicolumn{2}{|c|}{ Without perfusion } & \multicolumn{2}{|l|}{ Perfused } \\
\hline & Heart $^{\mathrm{a}}$ & Liver $^{\mathrm{a}}$ & Heart $^{\mathrm{a}}$ & Liver $^{\mathrm{a}}$ \\
\hline Lyso-7 PLA NC & $15.48 \pm 2.33$ & $51.17 \pm 7.47$ & $13.81 \pm 0.96$ & $49.90 \pm 5.69$ \\
\hline Free Lyso-7 & $3.96 \pm 1.42$ & $20.82 \pm 4.58$ & $3.60 \pm 0.49$ & $20.47 \pm 6.23$ \\
\hline
\end{tabular}

Administered dose: $1.6 \mathrm{mg} / \mathrm{kg}$.

a Mean of $\mu \mathrm{g} / \mathrm{g}$ of tissue $\pm \operatorname{SE}(n=4)$. used to produce effects of reduced neutrophil infiltration in vivo reported for Lyso-7 in mice [11] is in agreement with the above-mentioned calculations. Consequently, the intravenous doses of 1.6 and $2.2 \mathrm{mg} / \mathrm{kg}$ used in the present work are sufficient to activate PPARs and are likely to be sufficient to inhibit COX-1 and COX-2 in mice. Our data corroborates the previous observations that Lyso- 7 may be employed to treat neutrophil-mediated diseases and to reestablish damaged gastric microcirculatory networks in vivo as observed by Santin and co-workers [11].

In the biodistribution study described herein, the amounts of Lyso-7 in the liver and spleen were dramatically higher than the free drug when it was loaded in PLA-NC (Fig. 7), as expected, due to uptake by resident phagocytes of the mononuclear phagocytic system, as previously reported for the radiolabeled PLA-NC [13]. On the other hand, the increase in the Lyso-7 levels in the heart when administered associated with NC (3-fold, Fig. 7) is unexpected. In an attempt to better explain this point, the blood was removed from the organs by infusion with saline (Table 4) and the concentration in the organs tested again upon infusion. However, no significant differences were observed when comparing the organs with or without infusion, indicating that Lyso-7 concentration in the heart with the use of NC is not related to blood flow, but probably related to specific affinity of the compound for this organ after prolonged plasma exposure. However, this accumulation does not seem to be related to free Lyso-7 toxicity observed after intravenous administration in mice, because heart concentration increases with the administration of Lyso-7 loaded in NC and in this case, no toxicity was observed. Another hypothesis is that the uptake of Lyso-7-NC by different tissues in a modified biodistribution profile could reduce the toxicity. In fact, we observed a drastic modification in biodistribution of Lyso-7 after encapsulation.

When a drug is given in the form of an $i v$ bolus, the drug absorption can be considered instantaneous since the drug enters the circulation immediately. The rates at which various tissues will uptake the drug 
will depend on the drug's lipophilicity, the blood flow of the tissue, the drug molecular weight, and the binding affinity of the drug for the tissue [35]. After iv administration Lyso-7 is rapidly distributed throughout the mice body, as clearly evidenced by its fast concentration decay in plasma, reaching the highest concentrations in the different tissues in 10 min after administration (Figs. 6 and 7). This is probably a consequence of the high lipophilicity of Lyso-7 and of its ability to permeate membrane barriers, which induces fast tissue distribution and high apparent volume of distribution $\left(\mathrm{V}_{\mathrm{d}}\right)$. NC retains Lyso-7 in the plasma for longer times, which correlates with the slower release from the carrier or with the transfer of Lyso-7 from NC to plasma lipoproteins, as recently observed by Benita and co-workers with PLGA NC [29]. However, a fast decay of Lyso-7 concentration in the organs was observed up to 30 min upon injection for NC compared with free Lyso-7, indicating an efficient mechanism of organ clearance in the case of Lyso-7-NC (Fig. 7). Saxena and co-workers analyzed the biodistribution profile of the dye indocyanine green $(\log p=6)$ in PLGA NC and a similar profile of distribution was found in different organs [36]. They observed a reduction of the concentration of the dye associated to NC in different organs from 10 to $30 \mathrm{~min}$ upon injection of approximately 55\% in the liver, $20 \%$ in the spleen, $40 \%$ in the lungs, $17 \%$ in the heart and $30 \%$ in the kidneys. In our case similar values were found, with Lyso-7 $(\log p=5.6)$ organ clearance from 10 to $30 \mathrm{~min}$ upon injection of $56 \%$ in the liver, $45 \%$ in the spleen, $50 \%$ in the lungs, $40 \%$ in the heart and $20 \%$ in the kidneys. Similarly, in the first 10 min post-injection they observed an increase of indocyanine green $(\log p=6)$ of 1.8 -fold in the liver, 5.5fold in the spleen, 4-fold in the heart, 8-fold in the lungs and 5-fold in the kidneys, which corroborates with our results in the present work. The similarity between both studies could be attributed to their values of drug lipophilicity that play a major role in the drug permeation and elimination in different organs. Comparing our biodistribution results with those from other authors using the same type of nanocarrier, PLA NC with no surface modification, we found similar high accumulation in organs in the first minutes post-injection, for the PLA NC itself [13] and for the substance encapsulated, even if they differ largely in the chemical nature [37]. The affinity of a drug by a tissue strongly depends on its lipophilicity and permeability and unfortunately, the separation of free and encapsulated drug in plasma or tissue is a very difficult task to be performed experimentally after administration in vivo. Although the pharmacodynamic investigation of the pharmacological response was beyond the scope of this work, our results will provide a new tool to quantify Lyso-7 in above-mentioned tissues and to establish the required therapeutic dose range and Lyso-7 potency in further in vivo experiments.

As observed in Table 4, Lyso-7 shows a binding affinity to some tissues, such as the heart and liver. In this sense, the use of medium chain triglycerides (MCT) in the nanocapsule formulation could be partially responsible for the encapsulated Lyso-7 biodistribution. The use of MCT as NC core includes some advantages, such as its high capability to dissolve drugs compared with long chain triglycerides (LCT), low accumulation in adipose tissue and liver, faster plasma clearance, low promotion of pro-inflammatory mediator synthesis and resistance to peroxidation $[38,39]$. It has been suggested that substantial MCT amounts are cleared from blood as intact whole particles by different tissues [39-42], which in our case could increase the association of Lyso-7 with those same tissues.

Many attempts to define the fate of oil nanodroplets after intravenous administration of lipid-based particles have been reported already [38-42]. After intravenous injection, lipid nanodroplets can acquire apolipoproteins (apoC-II and apoE) by transfer from HDL and are generally metabolized as endogenous chylomicrons [38], or could be recognized as foreign body and cleared by the mononuclear phagocyte system, as reported in the literature [38-43].

MCTs are good substrates for endothelial bound lipoprotein lipase (LPL) that mediates triglyceride lipolysis [44-46]. Studies showed that inclusion of MCTs in TG mixtures accelerates lipolysis and leads to the rapid formation of small remnants that are efficiently taken up by tissues by a membrane fatty acid transporter highly expressed in the heart, adipose tissue and skeletal muscle $[40,44,45]$.

LPL expressed in the endothelium of different organs plays a major role on the insulin sensitizing effects induced by PPAR agonists [46]. In fact, MCT oil droplets increase the contact of the triglycerides with this enzyme in the endothelium and increase their transfer because MCT oil droplets have four-times higher solubility at the membrane/water interface compared to other triglycerides [39], used in solid or semisolid lipid nanodroplets, for example. As the endothelium in some tissues is one of the probable cell target of Lyso-7 new PPAR agonist, the association of this molecule with the MCT oily core of NC could introduce beneficial effects to improve drug targeting to endothelium, enhancing the insulin-sensitizing effects and the management of atherosclerosis related to this class of drugs [45-47]. Recently, it was reported that the treatment of LDLr $-/-$ mice with Lyso- 7 reduces the development of atherosclerotic lesions, reduces blood glucose levels, improves the lipid profile and downregulates CD40 and CD40L expression with no effect on body weight of the animals [48]. These results indicate that Lyso-7 attenuated atherosclerosis progression by modulating inflammation and lipid metabolism with limited side effects in mice [48].

Recently, Attili-Qadri et al. elegantly demonstrated that PLGA NCs are surface coated by proteins and phospholipids upon iv and oral administration [29]. This effect reduced the docetaxel release in plasma and significantly altered the organ biodistribution. Those observations are in agreement with our findings of higher retention of Lyso-7 PLA $\mathrm{NC}$ in the plasma compared to free drug. In the present study, encapsulation of Lyso-7 in the oily core of NC increased drastically plasmatic levels of Lyso-7 after iv administration, which could be related to the association of Lyso-7 with these lipoproteins following their distribution in tissues. As previously demonstrated, the greater the expression of LPL in the endothelium of a specific tissue, the greater the amount of lipid associated chylomicrons that are taken up [45-47]. In previous experiments, $5 \%$ of an injected dose of a label in chylomicron was recovered in the heart 2 min after $i v$ administration [49]. This may at least partially explain the high association of encapsulated Lyso-7 to the heart.

In fact, PPAR- $\gamma$ agonists, particularly pioglitazone, appear to have cardioprotective properties for patients with type 2 diabetes [50,51]. It is important to note that Lyso-7, which is also a PPAR- $\gamma$ agonist [10], could be an interesting alternative to induce cardioprotective effects, by taking advantage of its increased concentration in the heart provided by nanoencapsulation. As reviewed and discussed by Consoli \& Formoso, the use of TZD, particularly pioglitazone, has some advantages, at least until newer PPAR- $\gamma$ modulators will be able to retain the positive effects of pioglitazone with less adverse effects and greater tolerability [4]. Furthermore, it was reported that after a single intramuscular injection, PLGA nanoparticle loading pioglitazone accumulated in the capillary and arteriolar endothelium [14]. Also, these nanoparticles at the dose of $1 \mu \mathrm{g} / \mathrm{kg}$ resulted in higher angiogenic and atherogenic effects and improved the blood flow while a dose of $1000 \mu \mathrm{g} / \mathrm{kg}$ of free pioglitazone was necessary to produce the same effect [14]. Thus, it could be expected that the administration in PLA NC could be useful to improve the Lyso-7 concentration on the endothelium [11,48]. However, the potential cardiac side effects following chronic administration should be further investigated and detailed in vitro/in vivo studies are required.

Consistent with the prominent role of PPARs $(\alpha, \beta / \delta$, and $\gamma)$ in glucose metabolism and fatty acid oxidation and storage, tissues that are most active in these processes demonstrate high expression levels of PPARs [52,53]. In this respect, PPAR- $\delta$ is ubiquitously expressed, whereas PPAR- $\alpha$ is highly expressed in tissues such as the liver, kidney, heart, intestine, skeletal muscle and brown adipose tissue (BAT), and PPAR- $\gamma$ is expressed in adipose tissue, vascular and immune cells, retina, gut and brain [52]. Since PPAR expression presents a wide tissue 
distribution, PPAR synthetic ligands might also present pleiotropic effects, in addition to glucose- and lipid-lowering effects [53]. These include effects on the modulation of inflammatory signaling pathways in the heart [54], liver [55], kidney [56] and lungs [57], as well as on major players involved in the progression of diabetic nephropathy [56]. Thus, having much higher concentrations of Lyso-7 in the liver, heart, lungs and kidneys might affect pathophysiological processes and provide beneficial effects of this drug. Nonetheless, further investigation will be required to elucidate whether the local PPAR activation could also be involved in side effects ascribed to the TZD class of drugs, although these have not been observed with Lyso-7 until now $[10,11,48]$.

Thus, considering the benefits in terms of general acute toxicity and pharmacokinetic/biodistribution profiles after intravenous administration of Lyso-7 loaded in polymeric NC obtained in the present work, this new TZD, with high efficacy in vivo compared with other antiinflammatory agents $[10,11]$, is a good formulation candidate to be evaluated in experimental treatment of metabolic and degenerative disorders, such as type 2 diabetes mellitus and atherosclerosis [48].

\section{Conclusions}

NC formulation loading Lyso-7, a new thiazolidino-2,4-dione compound, was described herein. We firstly report a validated method to quantify Lyso-7 in NC and in biological samples (mice plasma and tissues) using a HPLC-UV method that is simple, fast, accurate, precise and specific. Pharmacokinetic and biodistribution data analysis indicates that association of Lyso-7 with the $\mathrm{NC}$ reduced the general toxicity and increased significantly plasmatic AUC and tissue exposure, particularly in the heart, where PPAR- $\gamma$ agonists induce protective effects [ 10 , 48]. This indicates that this formulation is a promising alternative for the administration of Lyso-7 in further pre-clinical studies.

\section{Acknowledgments}

The first author thanks INCT-if/MCT/CAPES-Brazil scholarship. IR Pitta, DSP Abdalla, and VCF Mosqueira are research fellows of CNPq, Brazil. We also thank Suely L. Galdino (in memoriam) for her important contribution to this work, Dr. G. Pound-Lana for Englishgrammar revision and the skillful help with SEM analysis of N. P. Sampaio from NanoLab CMM (Redemat/UFOP). This work was supported by NANOBIOMG-Network (\# 00007-14 and \# 40/11) and PPM grant (\# 00432-12) from FAPEMIG, Minas Gerais, Brazil.

\section{Appendix A. Supplementary data}

Supplementary data to this article can be found online at http://dx. doi.org/10.1016/j.jconrel.2015.04.033.

\section{References}

[1] H. Yki-Jarvinen, Drug therapy-thiazolidinediones, N. Engl. J. Med. 351 (2004) 1106-1118.

[2] M. Collin, C. Thiemermann, The PPAR- $\gamma$ ligand 15-deoxy $(812,14)$ prostaglandin J2 reduces the liver injury in endotoxic shock, Eur. J. Pharmacol. 29 (2003) 257-258.

[3] Y. Yumei, L. Yu, M. Saraswathy, C.T. Brian, B. Yochai, Pioglitazone protects the myocardium against ischemia-reperfusion injury in eNOS and iNOS knockout mice, Am. J. Physiol. Heart Circ. Physiol. 295 (2008) 2436-2446.

[4] A. Consoli, G. Formoso, Do thiazolidinediones still have a role in treatment of type 2 diabetes mellitus? Diabetes Obes. Metab. 11 (2013) 967-977.

[5] R.S. Rosenson, R.S. Wright, M. Farkouh, J. Plutzky, Modulating peroxisome proliferator-activated receptors for therapeutic benefit? Biology, clinical experience, and future prospects, Am. Heart J. 164 (2012) 672-680.

[6] F.D.T. Uchôa, T.G. Silva, M.C.A. Lima, S.L. Galdino, I.R. Pitta, T.D. Costa, Preclinical pharmacokinetic and pharmacodynamic evaluation of thiazolidinone PG15: an anti-inflammatory candidate, J. Pharm. Pharmacol. 61 (2009) 339-345.

[7] N.S. Murthy, V. Srinivasa, Screening of new synthetic thiazolidine-4-ones for antiinflammatory activity in albino rats, Indian J. Pharmacol. 35 (2003) 61-62.
[8] A.J.S. Góes, A.J. Alves, A.R. Faria, J.G. Lima, M.B.S. Maia, Synthesis and antiedematogenic activity of some $\mathrm{N}$-trypthophyl-5-benzylidene-2,4-thiazolidinedione and $\mathrm{N}$ trypthophyl-5-benzylidene-rhodanine derivatives, Quim. Nova 27 (2004) 905-910.

[9] L.C. Santos, F.D.T. Uchôa, A.R.P.A. Canas, I.A. Sousa, R.O. Moura, M.C.A. Lima, S.L. Galdino, I.R. Pitta, J. Barbe, Synthesis and anti-inflammatory activity of new thiazolidine-2,4-diones, 4-thioxothiazolidinones and 2-thioxoimidazolidinones, Heterocycl. Commun. 11 (2005) 121-128.

[10] J.R. Santin, F.DT. Uchôa, M.C. L Lima, M.M. Rabello, ID. Machado, M.Z Hernandes, A.A. Amato, F.A. Milton, P. Webb, F.A.R. Neves, S.L. Galdino, I.R. Pitta, S.H.P. Farsky, Chemical synthesis, docking studies and biological effects of a pan peroxisome proliferator-activated receptor agonist and cyclooxygenase inhibitor, Eur. J. Pharm. Sci. 48 (2013) 689-697.

[11] J.R. Santin, I.D. Machado, S.F.P. Rodrigues, S. Teixeira, M.N. Muscará, S.L. Galdino, I.R. Pitta, S.H.P. Farsky, Role of an indole-thiazolidine molecule PPAR pan-agonist and COX inhibitor on inflammation and microcirculatory damage in acute gastric lesions, PLoS One 8 (2013) e76894.

[12] S. Stegemann, F. Leveiller, D. Franchi, H. de Jong, H. Lindéne, When poor solubility becomes an issue: from early stage to proof of concept, Eur. J. Pharm. Sci. 31 (2007) 249-261.

[13] V.C.F. Mosqueira, P. Legrand, J.L. Morgat, M. Vert, E. Mysiakine, R. Gref, J.P. Devissaguet, G. Barratt, Biodistribution of long-circulating PEG-grafted nanocapsules in mice: effects of PEG chain length and density, Pharm. Res. 18 (2001) 1411-1419.

[14] R. Nagahama, T. Matoba, K. Nakano, S. Kim-Mitsuyama, K. Sunagawa, K. Egashira, Nanoparticle-mediated delivery of pioglitazone enhances therapeutic neovascularization in a murine model of hindlimb ischemia, Arterioscler. Thromb. Vasc. Biol. 32 (2012) 2427-2434.

[15] V.C.F. Mosqueira, P. Legrand, G. Barrat, Surface-modified and conventional nanocapsules as novel formulations for parenteral delivery of halofantrine, J. Nanosci. Nanotechnol. 6 (2006) 3193-3202.

[16] H. Fessi, F. Pusieux, J.P. Devissaguet, N. Ammoury, S. Benita, Nanocapsule formation by interfacial polymer deposition following solvent displacement, Int. J. Pharm. 55 (1989) R1-R4.

[17] C.S. de Paula, A.C. Tedesco, F.L. Primo, J.M. Vilela, M.S. Andrade, V.C.F. Mosqueira, Chloroaluminium phthalocyanine polymeric nanoparticles as photosensitisers: photophysical and physicochemical characterisation, release and phototoxicity in vitro, Eur. J. Pharm. Sci. 49 (2013) 371-381.

[18] M.A. Dobrovolskaia, J.D. Clogston, B.W. Neun, J.B. Hall, A.K. Patri, S.E. McNeil, Method for analysis of nanoparticle hemolytic properties in vitro, Nano Lett. 8 (2008) $2180-2187$.

[19] ICH harmonised tripartite guideline, International Conference on Harmonisation of Technical Requirements for Registration of Pharmaceuticals for Human Use, Validation of Analytical Procedures: Text and Methodology Q29(R1), ICH Steering Committee, Geneva, Switzerland 2005, pp. 1-13.

[20] U. Bhardwaj, D.J.A. Burgess, A novel USP apparatus 4 based release testing method for dispersed systems, Int. J. Pharm. 388 (2010) 287-294.

[21] L.T. Oliveira, G.M. Garcia, E.K. Kano, A.C. Tedesco, V.C.F. Mosqueira, HPLC-FLD methods to quantify chloroaluminum phthalocyanine in nanoparticles, plasma and tissue: application in pharmacokinetic and biodistribution studies, J. Pharm. Biomed. Anal. 56 (2011) 70-77.

[22] US Food and Drug Administration, Guidance for Industry, Bioanalytical Method Validation, Centre for Drug Evaluation and Research (CDER), Rockville, 2001.

[23] Y. Zhang, M. Huo, J. Zhou, S. Xie, PKSolver: an add-in program for pharmacokinetic and pharmacodynamic data analysis in Microsoft Excel, Comput. Methods Prog. Biomed. 99 (2010) 306-314.

[24] E.A. Leite, J.M.C. Vilela, V.C.F. Mosqueira, M.S. Andrade, Poly-caprolactone nanocapsules morphological features by atomic force microscopy, Microsc. Microanal. 11 (2005) 48-51.

[25] S.M. Moghimi, A.C. Hunter, C.M. Dadswell, S. Savay, C.R. Alving, J. Szebeni, Causative factors behind poloxamer 188 (Pluronic F65, Flocor ${ }^{\mathrm{TM}}$ )-induced complement activation in human sera. A protective role against poloxamer-mediated complement activation by elevated serum lipoprotein levels, Biochim. Biophys. Acta 1689 (2004) 103-113.

[26] P. Costa, S.J.M. Lobo, Modeling and comparison of dissolution profiles, Eur. J. Pharm. Sci. 13 (2001) 123-133.

[27] C.E. Mora-Huertas, H. Fessi, A. Elaissari, Polymer-based nanocapsules for drug delivery, Int. J. Pharm. 385 (2010) 113-142.

[28] A.L. Zampieri, F.S. Ferreira, E.C. Resende, M.P. Gaeti, D.G. Diniz, S.F. Taveira, E.M. Lima, Biodegradable polymeric nanocapsules based on poly(DL-lactide) for genistein topical delivery: obtention, characterization and skin permeation studies, J. Biomed. Nanotechnol. 9 (2013) 527-534.

[29] S. Attili-Qadri, N. Karra, A. Nemirovski, O. Schwob, Y. Talmon, T. Nassar, S. Benita, Oral delivery system prolongs blood circulation of docetaxel nanocapsules via lymphatic absorption, Proc. Natl. Acad. Sci. 110 (2013) 17498-17503.

[30] V.C.F. Mosqueira, P. Legrand, H.P. Alphandary, F. Puisieux, G. Barratt, Poly (D,Llactide) nanocapsules prepared by a solvent displacement process: influence of the composition on physicochemical and structural properties, J. Pharm. Sci. 89 (2000) 614-626.

[31] M. Hassellöv, J.W. Readman, J.F. Ranville, K. Tiede, Nanoparticle analysis and characterization methodologies in environmental risk assessment of engineered nanoparticles, Ecotoxicology 17 (2008) 344-361.

[32] E.A. Brender, M.D. Adorne, L.M. Colomé, D.S.P. Abdalla, S.S. Guterres, A.R. Pohlmann, Hemocompatibility of poly ( $\varepsilon$-caprolactone) lipid-core nanocapsules stabilized with polysorbate 80-lecithin and uncoated or coated with chitosan, Int. J. Pharm. 426 (2012) 271-279.

[33] V.C.F. Mosqueira, P.M. Loiseau, C. Bories, P. Legrand, J.-P. Devissaguet, G. Barratt, Efficacy and pharmacokinetics of intravenous nanocapsule formulations of 
halofantrine in Plasmodium berghei-infected mice, Antimicrob. Agents Chemother. 48 (2004) 1222-1228.

[34] E.A. Leite, A. Grabe-Guimarães, H.N. Guimarães, G.L.L. Machado-Coelho, G. Barratt, V.C.F. Mosqueira, Cardiotoxicity reduction induced by halofantrine entrapped in nanocapsule devices, Life Sci. 80 (2007) 1327-1334.

[35] L. Shargel, S. Wu-Pong, A. Yu, Applied Biopharmaceutics \& Pharmacokinetics, Sixth edition McGraw-Hill, 2012.

[36] V. Saxena, M. Sadoqi, J. Shao, Polymeric nanoparticulate delivery system for indocyanine green: biodistribution in healthy mice, Int. J. Pharm. 308 (2006) 200-204.

[37] M.A. Pereira, V.C.F. Mosqueira, V.A. Carmo, C.S. Ferrari, E.C. Reis, G.A. Ramaldes, V.N. Cardoso, Biodistribution study and identification of inflammatory sites using nanocapsules labeled with (99 m)Tc-HMPAO, Nucl. Med. Commun. 30 (2009) 749-755.

[38] M. Hultin, C. Carneheim, K. Rosenqvist, T. Olivecrona, Intravenous lipid emulsions: removal mechanisms as compared to chylomicrons, J. Lipid Res. 36 (1995) 2174-2184.

[39] M.N. Ton, C. Chang, Y.A. Carpentier, R.J. Deckelbaum, In vivo and in vitro properties of an intravenous lipid emulsion containing only medium chain and fish oil triglycerides, Clin. Nutr. 24 (2005) 492-501.

[40] J. Ferezou, A.C. Bach, Structure and metabolic fate of triacylglycerol and phospholipid-rich particles of commercial parenteral fat emulsions, Nutrition 15 (1999) 44-50.

[41] T. Sakaeda, K. Hirano, Effect of composition on biological fate of oil particles after intravenous injection of O/W lipid emulsions, J. Drug Target. 6 (1998) 273-284.

[42] P.C. Calder, D.L. Waitzberg, B. Koletzko, Intravenous lipid emulsions, World Rev. Nutr. Diet. 112 (2015) 57-62.

[43] A.L. Lainé, J. Gravier, M. Henry, L. Sancey, J. Béjaud, E. Pancani, M. Wiber, I. Texier, J.L. Coll, J.P. Benoit, C. Passirani, Conventional versus stealth lipid nanoparticles: formulation and in vivo fate prediction through FRET monitoring, J. Control. Release 28 (2014) 1-8.

[44] R. Savonen, M. Hiden, M. Hultin, R. Zechner, S. Levak-Frank, G. Olivecrona, T. Olivecrona, The tissue distribution of lipoprotein lipase determines where chylomicrons bind, J. Lipid Res. 56 (2015) 588-598.

[45] G. Olivecrona, T. Olivecrona, Triglyceride lipases and atherosclerosis, Curr. Opin. Lipidol. 21 (2010) 409-415.

[46] J.K. Kim, J.J. Fillmore, Y. Chen, C. Yu, I.K. Moore, M. Pypaert, E.P. Lutz, Y. Kako, W. VelezCarrasco, I.J. Goldberg, J.L. Breslow, G.I. Shulman, Tissue-specific overexpression of lipoprotein lipase causes tissue-specific insulin resistance, Proc. Natl. Acad. Sci. 98 (2001) 7522-7527.

[47] L. Fajas, M.B. Debril, J. Auwerx, PPAR gamma: an essential role in metabolic control, Nutr. Metab. Cardiovasc. Dis. 11 (2001) 64-69.

[48] F.A. César, M. Rudnicki, B. de las Heras, L. Boscá, M.C.A. Lima, I.R. Pitta, D.S.P. Abdalla New indole-thiazolidine attenuates atherosclerosis in LDLr $-/-$ mice, Vasc. Pharmacol. (2015)http://dx.doi.org/10.1016/j.vph.2015.03.009.

[49] T. Ruge, M. Bergö, M. Hultin, G. Olivecrona, T. Olivecrona, Nutritional regulation of binding sites for lipoprotein lipase in rat heart, Am. J. Physiol. Endocrinol. Metab. 278 (2000) E211-E218.

[50] J.P.H. Wilding, PPAR agonists for the treatment of cardiovascular disease in patients with diabetes, Diabetes Obes. Metab. 14 (2012) 973-982.

[51] L.C. Poulsen, M. Siersbæk, S. Mandrup, PPARs: fatty acid sensors controlling metabolism, Semin. Cell Dev. Biol. 23 (2012) 613-639.

[52] O. Braissant, F. Foufelle, C. Scotto, M. Dauca, W. Wahli, Differential expression of peroxisome proliferator-activated receptors (PPARs): tissue distribution of PPAR-alpha, -beta and -gamma in the adult rat, Endocrinology 137 (1996) 354-366.

[53] M. Ahmadian, J.M. Suh, N. Hah, C. Liddle, A.R. Atkins, M. Downes, R.M. Evans, PPAR signaling and metabolism: the good, the bad and the future, Nat. Med. 19 (2013) 557-566.

[54] E.R. Blasi, J. Heyen, M. Hemkens, A. McHarg, C.M. Ecelbarger, S. Tiwari, Effects of chronic PPAR-agonist treatment on cardiac structure and function, blood pressure, and kidney in healthy Sprague-Dawley rats, PPAR Res. (2009) 1-13, http:// dx.doi.org/10.1155/2009/237865. (237865).

[55] M.Y. Lee, R. Choi, H.M. Kim, E.J. Cho, B.H. Kim, Y.S. Choi, J. Naowaboot, E.Y. Lee, Y.C. Yang, J.Y. Shin, et al., Peroxisome proliferator-activated receptor $\delta$ agonist attenuates hepatic steatosis by anti-inflammatory mechanism, Exp. Mol. Med. 44 (2012) 578-585.

[56] P.A. Sarafidis, G.L. Bakris, Protection of the kidney by thiazolidinediones: an assessment from bench to bedside, Kidney Int. 70 (2006) 1223-1233.

[57] S.P. Lakshmi, A.T. Reddy, Y. Zhang, F.C. Sciurba, R.K. Mallampalli, S.R. Duncan, R.C. Reddy, Down-regulated peroxisome proliferator-activated receptor $\gamma(\operatorname{PPAR} \gamma)$ in lung epithelial cells promotes a PPAR $\gamma$ agonist-reversible pro-inflammatory phenotype in chronic obstructive pulmonary disease (COPD), J. Biol. Chem. 289 (2013) 6383-6393. 